\title{
Falcipains, Plasmodium falciparum Cysteine Proteases as Key Drug Targets Against Malaria
}

\author{
C. Teixeira ${ }^{1,2}$, J.R.B. Gomes ${ }^{2}$ and P. Gomes ${ }^{*}, 1$ \\ ${ }^{1}$ Centro de Investigação em Química da Universidade do Porto, Departamento de Química e Bioquímica, Faculdade de Ciências, \\ Universidade do Porto, R. Campo Alegre, 687, P-4169-007 Porto, Portugal \\ ${ }^{2}$ CICECO, Universidade de Aveiro, Campus Universitário de Santiago, P-3810-193 Aveiro, Portugal
}

\begin{abstract}
There is a high demand for new drugs against malaria, which takes millions of lives annually. The abuse of classical antimalarials from the late 1940's to the early 1980's has bred resistant parasites, which led to the use of more potent drugs that ended up by refueling the resistance cycle. An example is chloroquine, once highly effective but now virtually useless against malaria.

Structure-based rational drug design relies on high-resolution target structures to allow for screening of selective ligands/inhibitors. For the past two decades, and especially after the unveiling of the Plasmodium falciparum genome in 2002, enzymes of this lethal malaria parasite species have been increasingly attracting the attention of Medicinal Chemists worldwide as promising drug targets. There is particular emphasis on proteases having key roles on the degradation of host's hemoglobin within the food vacuole of blood-stage parasites, as these depend on such process for their survival. Among such enzymes, Plasmepsins (aspartic proteases) and, especially, Falcipains (cysteine proteases) are highly promising antimalarial drug targets. The present review will focus on the computational approaches made so far towards the unraveling of the structure, function and inhibition of Falcipains that, by virtue of their quite specific features, are excellent targets for highly selective inhibitors.
\end{abstract}

Keywords: Cysteine proteases, drug design, falcipain inhibitors, falcipains, malaria, Plasmodium Falciparum.

\section{INTRODUCTION}

Malaria is one of the earliest known diseases. Indeed, what would be afterward named malaria has been noted for more than 4000 years, being the first symptoms described in ancient Chinese medical writings [1]. Later, Hippocrates, the "Father of Medicine", also described the manifestations of malaria, and related them to the time of year and to where the patients lived [2]. But, the true cause of the disease became clear first in 1880, when the French researcher Laveran (Nobel Prize in Medicine 1907) discovered the malaria parasite in human blood [3]. In 1897 [4], the English physician Ross (Nobel Prize in Medicine 1902) and, in 1898 [5], the Italian zoologist Grassi, demonstrated that the parasite was injected into the human bloodstream through the bite of an infected female mosquito [6].

Today, malaria remains one of the most important infections in human, being the most widespread and severe tropical disease [7]. It is mostly present in Africa, Asia and South America and affects huge numbers of people: up to 300 million clinical cases, mainly children, emerge each year causing near 1 million deaths [8]. The five different species that cause human malaria are: Plasmodium (P.) vivax, $P$. malariae, $P$. ovale, $P$. falciparum ( $P f$, the deadliest) and $P$. knowlesi (recently found to infect humans) [9].

Several organized efforts to control the transmission and eradicate the disease have been made through history [10]. Two main approaches have been employed: killing the parasite and killing the parasite vector. Also, various attempts to develop antimalarial vaccines can be added to the arsenal of control efforts [11]. These efforts achieved a regional elimination in Southern Europe and in some countries in North Africa and in the Middle East. Despite initial success, there was a complete failure to eradicate malaria in many countries due to a number of factors. Since then, we have been witnessing to a massive 2-3 fold increase in occurrences globally $[12,13]$.

Complex life cycle, disease spreading through a mosquito vector, resistance of the mosquito to insecticides and a rapidly growing

*Address correspondence to this author at the Centro de Investigação em Química da Universidade do Porto, Departamento de Química e Bioquímica, Faculdade de Ciências, Universidade do Porto, R. Campo Alegre, 687, P-4169-007 Porto, Portugal; Tel: +351 220402563: Fax: +351 220402563; E-mail: pgomes@fc.up.pt resistance of the malaria parasite to the available drugs are the major reasons behind malaria being such a burden to humanity [1416]. The parasite is developing new ways of escaping drugs, such as antifolates and chloroquine, which was by far the most frequently used antimalarial for half a century [17-19], by random mutations [20]. Thus, the existing drugs become less effective against their targets and finally completely useless against some strains. Although drug combinations including potent antimalarials such as artemisinin and its derivatives [21-23], have been effective, there is an urgent need to identify new therapeutic targets and to develop drugs aimed at such targets.

For the past two decades, and especially after the unveiling of the Plasmodium falciparum genome in 2002 [24], new potential drug targets for inhibitor development research have been proposed $[25,26]$. Among these, falcipains (cysteine proteases) from $P$. falciparum are highly promising target enzymes, which play a key role in hemoglobin degradation in trophozoites [27-29]. In this article, we will review the main characteristics of falcipains, their protein inhibitors, their mode of action and structural aspects, with a special focus on the advances of computational approaches employed in the development of falcipain inhibitors.

\section{ANTIMALARIAL THERAPY}

Understanding the interplay of the malaria parasite with its cellular host provides the biological basis for attempting the control/eradication of this epidemic. The complete life cycle of malaria parasites consists of two basic cycles, an asexual cycle in the human host and a sexual cycle in the mosquito host [30]. In the former situation, the asexual cycle can be further divided into a liver stage (or a pre-erythrocytic stage) and an erythrocytic stage [30]. A schematic representation of the transmission cycle of this parasite appears in (Fig. 1).

Infection begins when sporozoites are injected into the blood stream from the salivary glands of mosquitoes when they bite the human host for their blood meal. The sporozoites then travel to the liver and invade hepatocytes, where they are converted, through an asexual transformation, to trophozoites, which in turn divide into several schizonts, eventually generating merozoites. After being multiplied in huge numbers, these merozoites rupture the hepatocytes and are released into the blood stream, where they invade red blood cells (RBC), initiating the erythrocytic stage. This stage is 


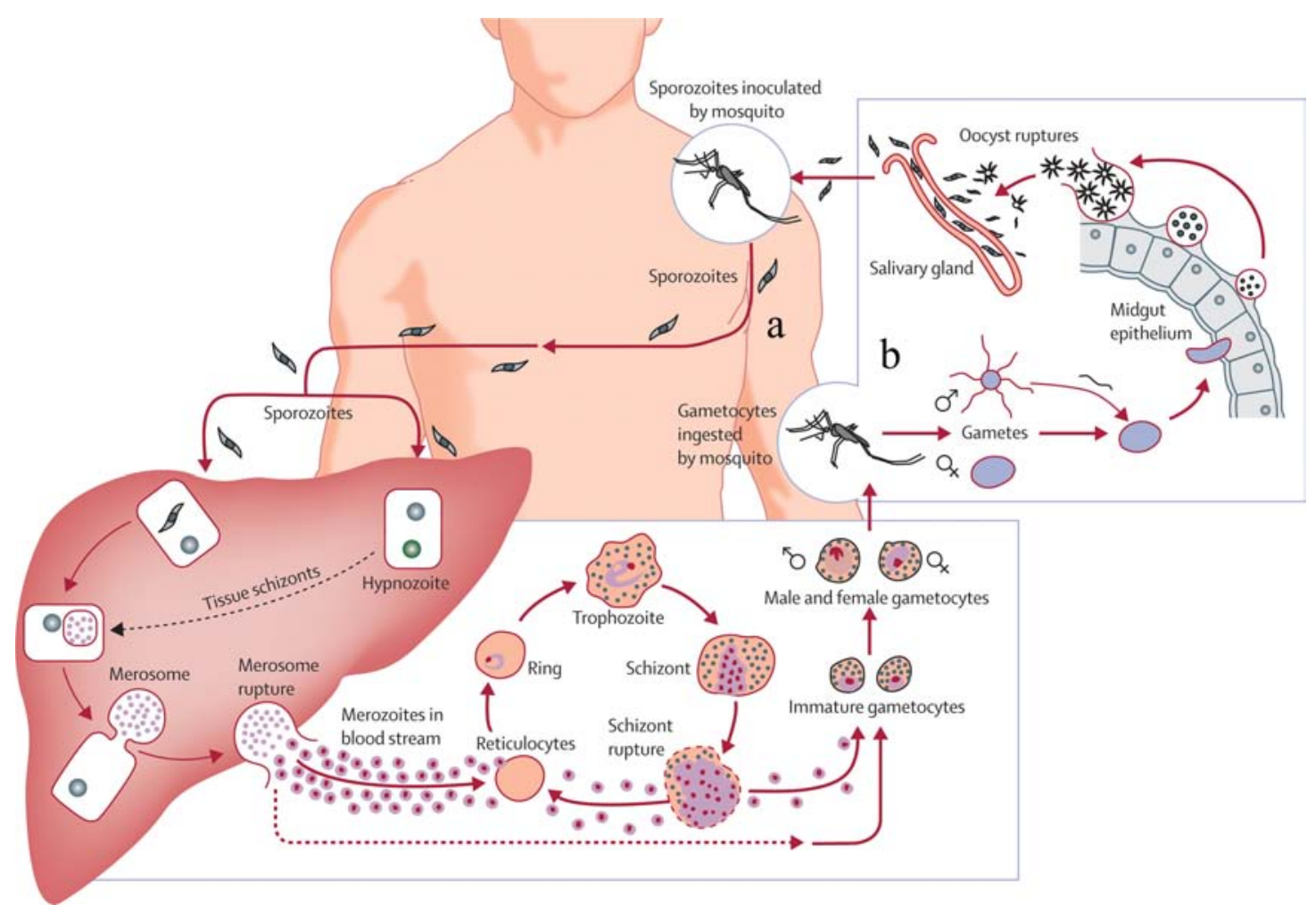

Fig. (1). The life cycle of Plasmodium falciparum, where a and b represent the asexual cycle in human host and the sexual cycle in the mosquito, respectively. Figure reprinted from ref. [31] with permission from Elsevier.

generally similar to the liver stage, in the sense that parasite's multiplication in RBC involves formation of merozoites that multiply through a second phase of asexual replication, resulting in the production of more merozoites that are released from infected RBC to invade new ones. This process is repeated over and over again and is responsible for the symptomatic phase of malaria. Sometimes, during this endo-erythrocytic stage, other forms of the parasite emerge as gametocytes, sexually differentiated forms that, when taken up by a feeding mosquito, will complete the sexual cycle within the mosquito gut until new sporozoites are formed and migrate to the insect's salivary glands, for a next round in the spreading of infection.

Though the complex life cycle of the malaria parasite is behind the many difficulties felt in suppressing the disease, it offers several possible alternatives for the control of infection. One of them is mosquito eradication through extensive use of insecticides and habitat transformations as, e.g., use of bed nets. This would be, probably, the most desirable method, but its successful implementation is extremely difficult due to the large areas involved, not to mention the development of insecticide-resistant mosquito strains. Alternatively, the human host can be immunized against the malaria parasite through vaccines. Several possible vaccines have been under development, mainly focused on the pre-erythrocytic stage. Although some projects are particularly promising in this area [32, 33 , a functional vaccine is not available yet and there are no prospects for becoming available soon [34]. So, drug therapy remains the mainstay of treatment and prevention of this disease.

The discovery of drugs to combat malaria has to a large extent been serendipitous, and the mechanism of action of many agents is still partially or totally unknown. Available antimalarials target mainly blood-stage parasites. Chloroquine (Fig. 2) and other quinine alkaloid derivatives have been the XXth century drugs in most parts of malaria-endemic regions of the world. Chloroquine appears to act by blocking the biocrystallization of heme, while mechanisms for related drugs, including quinine, are unknown. Antifolate drugs, such as pyrimethamine (Fig. 2), another large and classical group of antimalarials, inhibit folate metabolism. Some general antibiotics have also been found to exhibit antimalarial activity $[19,21,35$, 36].<smiles>CCc1nc(N)nc(N)c1-c1ccc(Cl)cc1</smiles><smiles></smiles><smiles>CCN(CC)CCCC(C)Nc1ccnc2cc(Cl)ccc12</smiles>

Fig. (2). Molecular structures of pyrimethanine, artemisinim and chloroquine.

During the last decades, a new type of antimalarials based on the artemisinin scaffold (Fig. 2) has emerged. These molecules have been found to effectively reduce parasitemia but their mechanisms of action still remain unknown. Unfortunately, parasite resistance is rendering previous antimalarial medicines ineffective in most parts of the world. This resistance to antimalarial drugs arises as a result of spontaneously occurring mutations that affect the structure and 
Table 1. Summary of Some Novel Targets in P. falciparum with Candidate Inhibitors Currently Under Investigation

\begin{tabular}{|c|c|c|c|}
\hline Enzyme's function & Enzyme / receptor & Candidate inhibitor & Refs \\
\hline \multirow{9}{*}{$\begin{array}{l}\text { Macromolecular and metabolite } \\
\text { synthesis }\end{array}$} & 5-enolpyruvyl shhikimate 3-phosphate synthase & Glyphosate & {$[44]$} \\
\hline & Phospholipid biosynthesis & G25 & [46] \\
\hline & DOXP reductoisomerase & Fosmidomycin & {$[47]$} \\
\hline & ACCase & Acryloxy phenoxy propionate & [48] \\
\hline & $\mathrm{Fab} \mathrm{A} / \mathrm{Z}$ & NAS-21, NAS-91 & {$[49]$} \\
\hline & $\mathrm{FabH}$ & Thiolactomycin & {$[50]$} \\
\hline & FabI & Triclosan & [51] \\
\hline & HGPRT & Immucilin-H & {$[52]$} \\
\hline & Cytochrome $c$ oxidoreductase & Atovaquone & {$[53]$} \\
\hline \multirow{2}{*}{ Membrane transport and signaling } & Folate-biopterin transporters & Methotrexate, probenecid & {$[54]$} \\
\hline & Hexose transporter & O-3-hexose derivatives & {$[55]$} \\
\hline \multirow{2}{*}{ Hemoglobin degradation } & Plasmepsins, falcipains & Leupeptin, pepstatin and several other compounds & {$[56,57]$} \\
\hline & Hemozoin & Triacyl carbinol and several other compounds & {$[58]$} \\
\hline
\end{tabular}

DOXP: 1-deoxy-D-xylulose-5-phosphate; ACCase: acetyl-CoA carboxylase; FabA/Z: $\beta$-hydroxy acyl-ACP dehydratase; FabH: 3-ketoacyl-ACP synthase III; FabI: enoyl-ACP reductase; HGPRT: hypoxanthine-guanine-xanthine phosphoribosyltransferase.

activity at the molecular level of the drug target in the malaria parasite or affect the access of the drug to that target [37]. To date, clinically relevant resistance has emerged towards all classes of antimalarial drugs except for the artemisinins [16]. Despite not having been encountered resistance to artemisinin-based antimalarials in the field yet, prominent reports have recently noted delayed parasite clearance suggestive of decreased drug sensitivity in Southeast Asia [38-40].

Early diagnosis and prompt treatment are fundamental components of the WHO global strategy for malarial control [41]. Also, combination therapy of the effective antimalarial drugs available, such as artemisinin and its analogues, is thought to be essential for preserving the efficacy of antimalarials and prolonging their useful therapeutic life [41, 42]. Therefore, there is unanimity that substantial scientific effort should be devoted to the discovery of additional novel therapeutic targets in order to develop new and effective antimalarials.

Since the unveiling of the P. falciparum genome in 2002 [24], a number of potential targets for drug intervention have emerged [19, 43, 44] (Table 1). These potential antimalarial drug targets can be broadly classified into three categories, according to their function in the parasite's life cycle [25, 45]: i) targets involved in macromolecular and metabolite synthesis, ii) targets engaged in membrane transport and signaling, and iii) targets involved in hemoglobin degradation.

Despite the existence of several potential targets, the present review is particularly focused on inhibition of falcipains, which belong to the cysteine protease family of $P$. falciparum and are involved in hemoglobin metabolism, for which an extensive amount of results was already published in the literature.

\subsection{Hemoglobin Metabolism}

Hemoglobin is the most abundant protein in erythrocytes, and becomes completely degraded after parasite entry. During the erythrocytic stage, the parasite uses host hemoglobin as a food source $[59,60]$. Given that Plasmodia have limited capacity for de novo amino acid biosynthesis, it has been suggested that hemoglobin degradation products are essential for the parasite's own protein biosynthesis, therefore, for its survival. Amino acids from hemoglobin proteolysis also appear to be required for energy metabolism [60] and several studies have proven hemoglobin metabolism to be essential for parasite survival $[61,62]$. In order for this degradation to occur, hemoglobin is initially transported to the parasite's acidic food vacuole where it expresses a number of active proteases [63] ready to proceed to this degradation.

The spectrum of proteolytic activity in the malarial parasite can be divided into two functional groups: i) proteases that are involved in invasion and rupture of erythrocytes and ii) proteases that are involved in hemoglobin hydrolysis [64]. Relative to the later, there are two relevant protease families: aspartic proteases and cysteine proteases, called plasmepsins and falcipains, respectively.

The degradation process appears to follow an ordered pathway $[65,66]$, which is outlined in Fig. (3). It has been difficult to determine whether a plasmepsin or falcipain catalyzes the initial cleavage [67]. However, it has been suggested that an initial cleavage between Phe33 and Leu34 in the hinge region, of the domain responsible for holding together the oxygen bound tetramer, unravels hemoglobin to expose it to further cleavage $[66,68]$. Subsequent cleavage into smaller peptides is catalyzed by both plasmepsins and falcipains [69]. The metalloprotease falcilysin and dipeptidyl aminopeptidase-1 (DPAP1) cleave the resulting small peptides to even shorter oligopeptides $[65,70]$ that are finally hydrolised to free amino acids by aminopeptidases [71].

During the hemoglobin degradation process, free heme is released and oxidized from the ferrous $\left(\mathrm{Fe}^{+2}\right)$ state to the ferric $\left(\mathrm{Fe}^{+3}\right)$ hematin [69]. Both heme and hematin are potentially toxic to the parasite [72]. To counter this, the parasite has evolved a detoxification system resulting in the formation of $\beta$-hemozoin pigment, an inert crystalline hematin polymer $[69,73]$.

From the above, it is understandable that plasmepsins and falcipains, proteases that play vital roles in the erythrocytic cycle of malaria parasites, have generated substantial interest [74]. Inhibitors of these enzymes have been shown to block the hydrolysis of hemoglobin [75] and to inhibit the rupture of erythrocytes [76], thus suggesting that they are valuable candidate therapeutic targets [28, $77,78]$ in the development of new antimalarials.

\section{FALCIPAIN CYSTEINE PROTEASES}

Cysteine proteases were given this name due to the function of a catalytic cysteine. This amino acid catalyzes protein hydrolysis via nucleophilic attack to the carbonyl carbon of a susceptible bond. Falcipains are the best characterized cysteine proteases of the malaria parasite. For instance, analysis of the P. falciparum genome sequence suggested the existence of a family of four falcipains: 


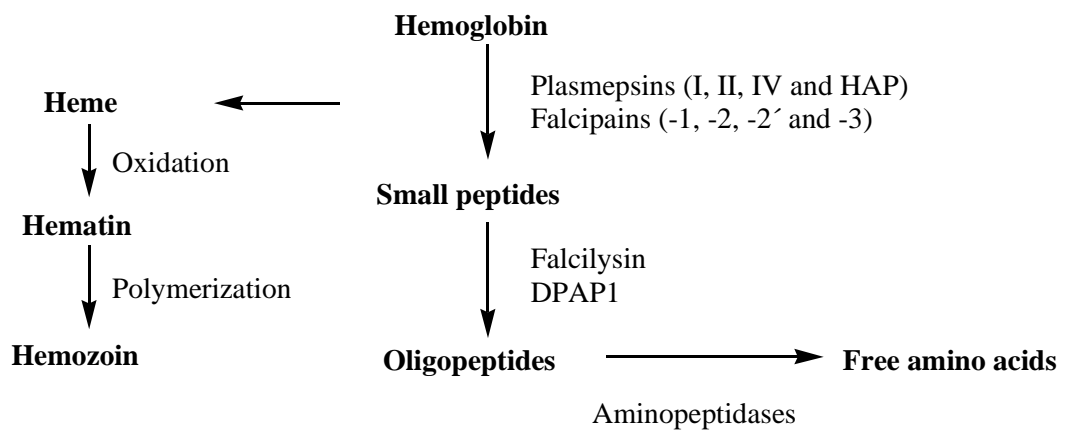

Fig. (3). The degradation process of hemoglobin in the P. falciparum food vacuole.

falcipain-1 (FP1), falcipain-2 (FP2), falcipain-2' (FP2') and falcipain-3 (FP3) [29, 79-81]. FP1 is encoded on chromosome 14 and is distantly related to the other falcipains in terms of sequence $(<40 \%$ amino acid identity) and function [82]. Its exact physiological role has yet to be elucidated. However, some studies suggested that FP1 could be important in oocyst production during parasite development in the mosquito midgut [83] and also could help in the invasion of the host cell by P. falciparum [84, 85]. FP2, FP2' and FP3, encoded within a $12,5 \mathrm{~kb}$ stretch of chromosome 11 , are closely related and appear to be the key hemoglobinases in the acidic food vacuole $[29,86]$. Also, they are believed to be involved in the transformation of pro-plasmepsins into the mature active enzymes [87]. Falcipain-2 is the best studied among this family of cysteine proteases [28]. FP2' is thought to arise by gene duplication. It presents a 93\% amino acid similarity with FP2 [86], hence suggesting possible physiological role as hemoglobinase $[81,88]$. FP2 and FP3 present a high similarity in sequence (68\% identity), share similar sized prodomains and include an unusual amino-terminal extension of the catalytic domain that is not found in FP1 [28]. Studies with recombinant proteins suggested that these proteases are synthesized as integral membrane proteins, and subsequently hydrolyzed to release soluble active proteases [80]. Both require a reducing environment and acidic $\mathrm{pH}$ for optimal activity. However, for FP3, it appears that hydrolysis is delayed until it enters an acidic environment. At acidic pH, FP3 is more active and stable, presenting a higher activity against native hemoglobin than FP2 [28]. It has been discovered that, despite the concentration of FP2 in trophozoites being 1.8 times that of FP3, the latter seems to cleave hemoglobin about twice as rapidly as the former. This indicates that the relative contribution of the two enzymes to hemoglobin degradation is essentially equivalent [80]. Also, another study revealed that the loss of FP2 is probably compensated by the increased expression of FP2' and/or FP3, thus suggesting the overlapping functions performed by the falcipains [79]. These findings suggest that drug development focused on falcipains must take into account simultaneous inhibition of all the essential falcipains. Nonetheless, given the yet unveiled role of FP1 and the apparent equivalence of FP2 to FP2', it is of common sense that a potent inhibitor against both FP2 and FP3 will most probably impair hemoglobin degradation to levels that are lethal for the parasite. Therefore, the present review will be focused exclusively on falcipain-2 and falcipain-3.

\subsection{Falcipain Structure and Specificity}

The falcipains are all fairly typical papain-family cysteine proteases, though they have some rather uncommon features, e.g. exceptionally large prodomains, predicted membrane spanning sequences within the prodomains, an unusual insertion between highly conserved residues near the carboxy terminus $[29,80]$ and an additional disulfide bond required for their proteolytic activity [89]. A feature that falcipains share with other papain-family cysteine proteases is the ability of small peptides from the prodomain of FP2/3 to become potent inhibitors of these enzymes [90, 91].
Furthermore, falcipains also adopt the classical papain-like fold in which the protease is divided into $\mathrm{L}$ (left) and $\mathrm{R}$ (right) domains (Fig. 4).

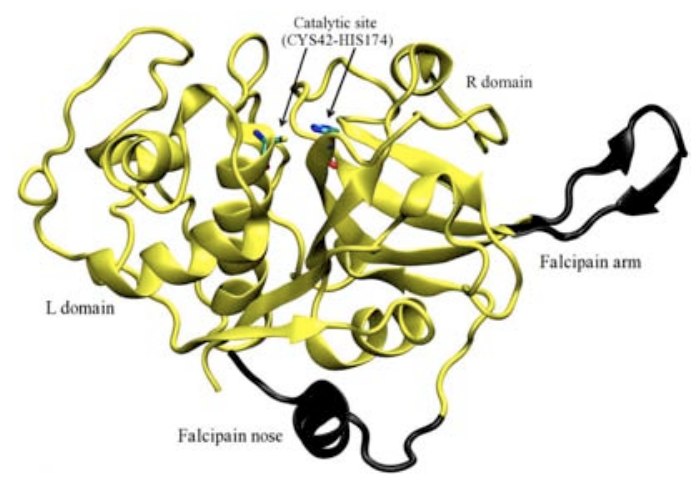

Fig. (4). Representation in new cartoon of the structure of falcipain-2 (PDB code: $3 \mathrm{BPF}$ ) with the L domain (Left) and the $\mathrm{R}$ (Right) domain colored in light grey. The N-terminal extension $\left(\mathrm{FP}_{\text {nose }}\right)$ at the most right and the $\mathrm{C}$ terminal insertion $\left(\mathrm{FP}_{\mathrm{arm}}\right)$ at the bottom are colored in dark grey. Adapted from [92].

Homology models and X-ray crystallography studies on falcipains provided important structural information about these enzymes. FP2 and FP3 are single polypeptide chains of 241 and 243 amino acids, respectively. The catalytic residues CYS42, HIS174 and ASN204 for FP2 and CYS44, HIS176 and ASN206 for FP3 are located at the junction between domains $\mathrm{L}$ and $\mathrm{R}$. The catalytic site is formed by a cysteine and a histidine, whose side chains form a thiolate/imidazolium ion pair, and also by an asparagine, which has a crucial role in the appropriate orientation of the ion pair [93]. A schematic representation of the mechanism of action is outlined in Fig. (5).

One of the key events in the catalytic hydrolysis of hemoglobin is the nucleophilic attack of the thiolate anion to the appropriate electron deficient carbonyl group of the substrate. This 1,2-addition leads to a negatively charged tetrahedral intermediate that was found to be stabilized by the "oxyanion hole" formed by the side chains of GLN36 and TRP206, in FP2, and by GLN38 and TRP208 in FP3. Schechter and Berger [94] have established a nomenclature to designate substrate residues and the corresponding enzyme subsites, based on their positions relative to the scissile amide bond (Fig. 6). Substrate residues $(\mathrm{P})$ in the direction from the scissile bond towards the $\mathrm{C}$-terminal are denoted primed, while residues in the N-terminal direction are nonprimed. The same notation is also applied to the enzyme subsites (S), or pockets, occupied by the substrate.

The active site of falcipains (Fig. 7) is generally formed by four pockets: S1, S2, S1' and S3 [95]. The S1 pocket is the least defined 


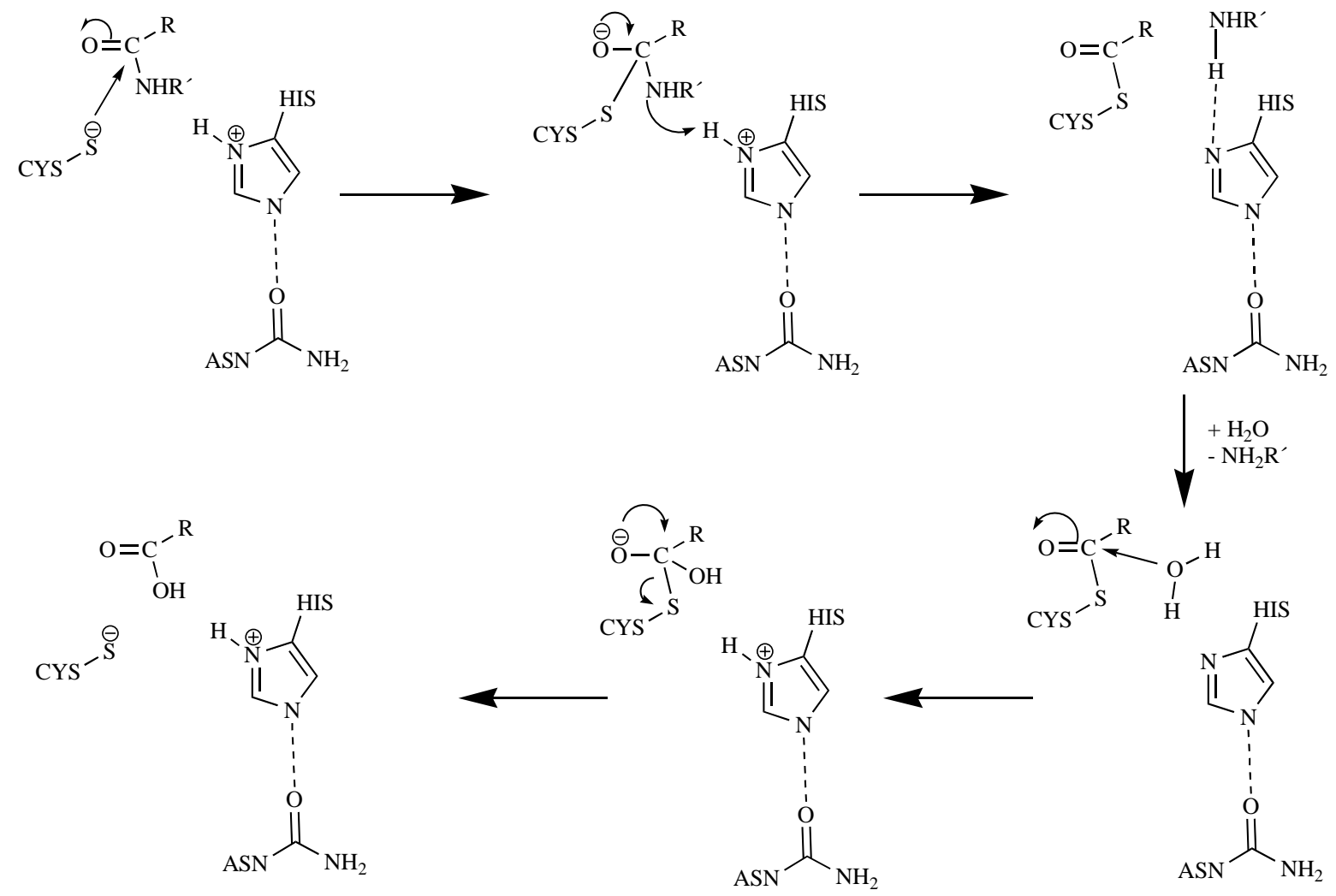

Fig. (5). Schematic reaction mechanism of the cysteine protease mediated cleavage of a peptide bond.

of the four grooves and, usually, includes the glutamine of the "oxyanion hole". The most well-defined pocket is S2, which seems to govern specificity towards FP2 and/or FP3, and to prefer substrates bearing a LEU in the corresponding P2 site $[29,80]$. The $\mathrm{S} 1$ ' pocket contains a highly conserved tryptophan, which is known to participate in hydrophobic interactions with substrates. Finally, a glycine-rich region of the binding site represents the $\mathrm{S} 3$ groove.

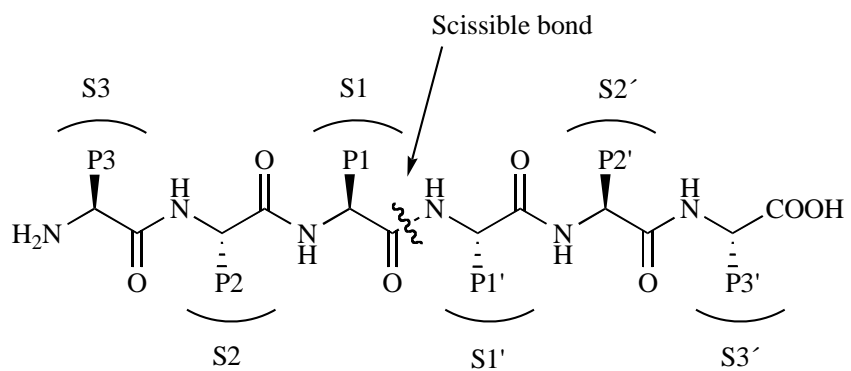

Fig. (6). Schechter and Berger's nomenclature for substrate residues $(\mathrm{P})$ and their corresponding binding sites (S).

Of interest, FP2 and FP3 structures contain two unique features assigned as FP2/3 nose and FP2/3 arm [92] (Fig. 4). The FP2/3 nose motif, situated at the $\mathrm{N}$-terminus, is required for folding, while the $\mathrm{FP} 2 / 3_{\text {arm }}$ contains a $\mathrm{C}$-terminal insertion and mediates interaction between the falcipains and hemoglobin independent of the enzyme's active site [92].

\subsection{Falcipain Inhibitors: Potential Antimalarial Drugs}

During the last two decades, we have witnessed an impressive scientific effort to discover new targets for antimalarial therapy, and among them, the falcipain family proteases, namely FP2 and FP3, have been defined as promising drug targets $[28,60]$. Indeed, most studies in this area have shown that falcipain inhibitors prevent hemoglobin hydrolysis, block parasite development and cure murine malaria [75, 78, 96-99].

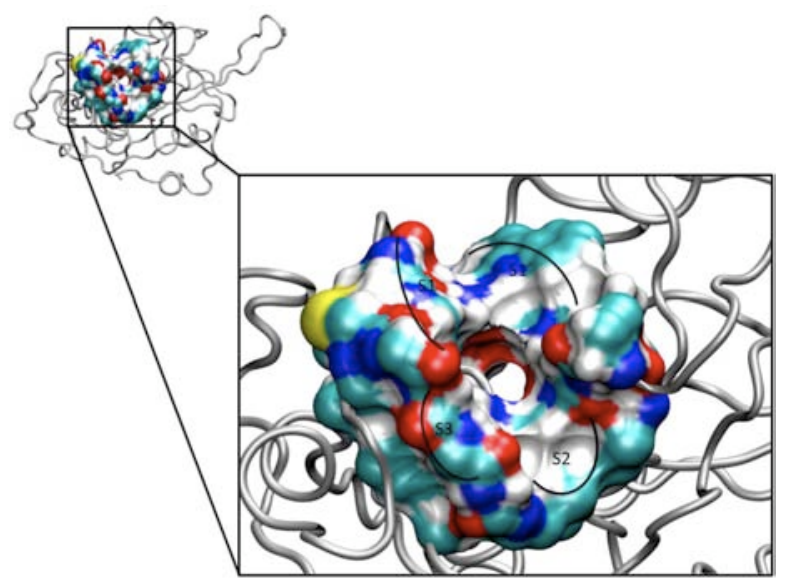

Fig. (7). Representation of the falcipain-3 catalytic site surface showing the $\mathrm{S} 1, \mathrm{~S} 1{ }^{\prime}, \mathrm{S} 2$ and $\mathrm{S} 3$ pockets.

To date, many compounds have been identified as inhibitors of falcipains, which are able to block the enzyme's activity by forming a reversible or irreversible covalent bond with the active site cysteine. These falcipain inhibitors can be broadly divided into three categories [57]: i) peptide-based inhibitors, ii) peptidomimetic inhibitors and iii) nonpeptidic inhibitors. Most of the falcipain inhibitors identified so far are peptide-based inhibitors [57] (Fig. 8). This category includes peptidyl fluoromethyl ketones [100], peptidyl vinyl sulfones [101, 102], peptidyl aldehydes and $\alpha$-ketoamide derivatives [103], epoxysuccinyl derivatives [104] and peptidyl azirines [105]. Peptidyl aldehydes and $\alpha$-ketoamides inhibit FPs in 
<smiles>N=C(N)NCCC[C@H](NC(=O)[C@H](Cc1ccccc1)NC(=O)OCc1ccccc1)C(=O)CF</smiles>

Z-Phe-Arg- $\mathrm{CH}_{2} \mathrm{~F}$

(Peptidyl fluoromethyl ketone)<smiles>CC(C)C[C@H](NC(=O)N1CCOCC1)C(=O)N[C@@H](C=O)CCc1ccccc1</smiles>

Mu-Leu-hPhe-al (Peptidyl aldehyde)

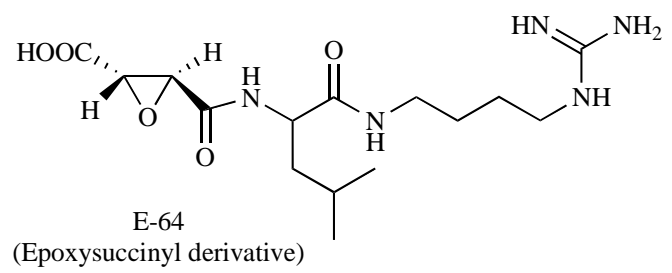

Fig. (8). Molecular structures of some peptide-based falcipain inhibitors.

a reversible manner, while the others are irreversible inhibitors. These classes of compounds were found to inhibit enzymatic activity of FPs at very low nanomolar range. However, their utility as therapeutic agents is limited for their susceptibility to protease degradation and their poor absorption through cell membranes [57].

A common strategy to avoid the therapeutic limitations of peptide-based inhibitors is to lock a defined conformation of the peptide into a rigid scaffold. This strategy yielded the peptidomimetic FPs inhibitors (Fig. 9), including compounds based on 1,4benzodiazepine [106] and pyridone ring [107] scaffolds, which are able to reversibly block the enzyme. As far as nonpeptide FP inhibitors are concerned (Fig. 9), these include chalcones [108], which are biosynthetic precursors of flavonoids, isoquinolines $[95,96]$ and thiosemicarbazones [109].

Historically, novel enzyme inhibitors are discovered either by serendipity or by screening of natural and synthetic compounds. Over the past few years, through a better understanding of biochemical processes and the emergence of powerful computational tools, rational drug design has emerged complementarily to these techniques. The advances on computational approaches towards the development of novel falcipain inhibitors are reviewed in the following section.

\section{CHEMOINFORMATICS AND MODELING STUDIES OF FALCIPAINS AND INHIBITORS}

Nowadays, molecular modeling is considered as a field related to the use of diverse strategies, e.g. construction of $3 \mathrm{D}$ protein<smiles>CC(C)C[C@H](NC(=O)N1CCOCC1)C(=O)N[C@H](/C=C/S(=O)(=O)c1ccccc1)CCc1ccccc1</smiles>

Mu-Leu-hPhe-VSPh

(Peptidyl vynil sulfone)<smiles>CC(C)C[C@H](NC(=O)N1CCOCC1)C(=O)N[C@@H](CCc1ccccc1)C(=O)N[C@@H](Cc1ccccc1)C(=O)C(N)=O</smiles>

$\mathrm{Mu}-\mathrm{Leu}-\mathrm{hPhe}-(\mathrm{CO})-\mathrm{Phe}-\mathrm{NH}_{2}$ $(\alpha$-ketoamide)<smiles>[R]OC(=O)C1NC1C([R20])=O</smiles>

Peptydil aziridine derivatives

$\mathrm{R}_{1}=\mathrm{Et}, \mathrm{H}$

$\mathrm{R}_{2}=$ aminoacid structures by homology modeling, analysis of 3D databases, diversity analysis, docking of ligands or continuum methods, for modeling and deducing information of a system at the atomic level. Identification of molecular groups involved in the interaction(s) of a chemical moiety or entity with a specific receptor helps to understand the molecular mechanism(s) responsible for their specific biological activities. Consequently, acquired knowledge is then applied to design new active molecules that can be successfully used as bioactive compounds. Among other factors, simulation accuracy is limited to the precision of the constructed models. When possible, computational simulations have to be compared with experimental results for confirmation of the model correctness and, if necessary, gathered information is used to modify the models for obtaining better representations of the system. Other factors governing the accuracy of the simulations are related with the computational approach used to compute interesting properties of the model system, e.g. interaction energies, structures, etc., which turns the field of molecular modeling quite broad and varied. A summary of the molecular modeling tools commonly employed in drug development will be given in the forthcoming sections.

\subsection{Overview of Computational Methods in Drug Development}

The computer simulation techniques can be broadly classified into three main areas: molecular mechanics, molecular dynamics and quantum mechanics. The latter technique is subdivided into two main categories, semi-empirical molecular orbital methods and $a b$ initio calculations. The most accurate approach is the ab-initio method, which calculates properties of a system from first princi- 
PEPTIDOMIMETIC FP INHIBITORS

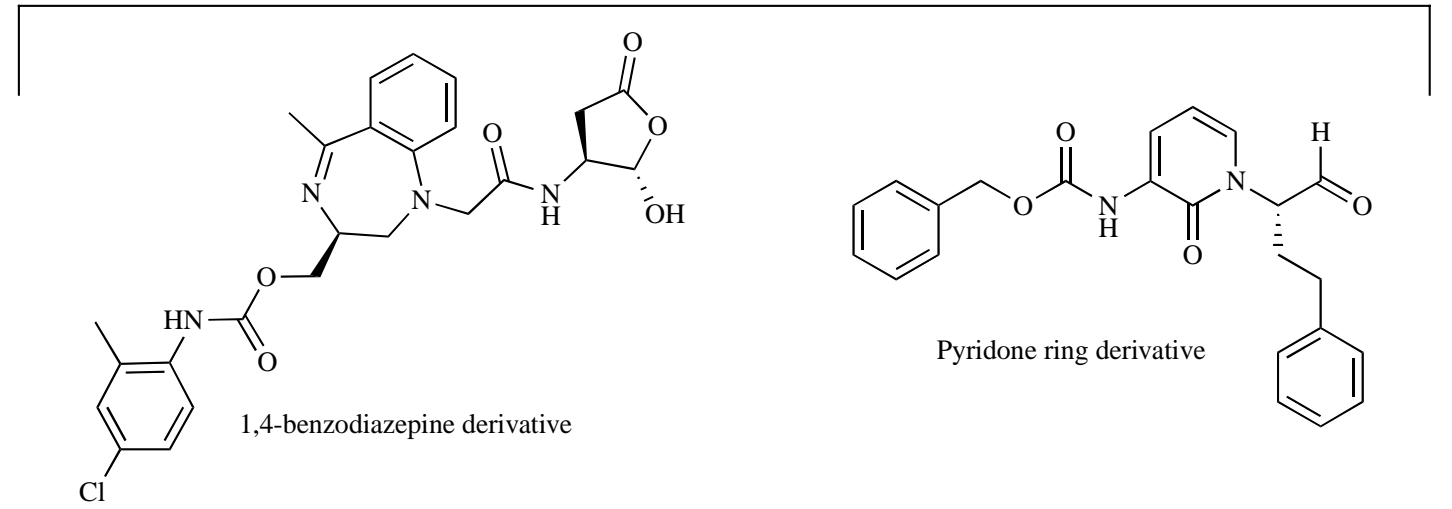

NONPEPTIDIC FP INHIBITORS

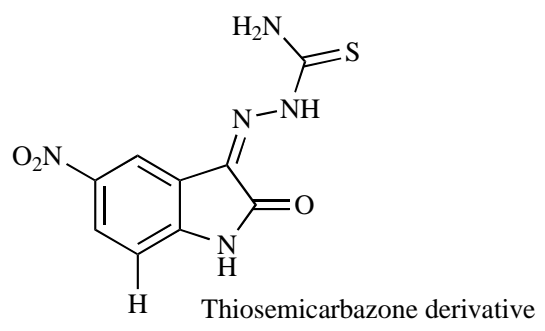<smiles>COc1cc2ccnc(-c3ccc(OCc4ccccc4)cc3)c2cc1OC</smiles><smiles>O=C(Nc1ccc(Cl)cc1)Nc1ccc(C(=O)/C=C/c2ccc(F)cc2F)cc1</smiles>

Calchone derivative

Fig. (9). Molecular structures of peptidomimetic and nonpeptidic falcipain inhibitors.

ples by solving Schrödinger equations numerically. In this method, all electrons are treated explicitly and the interactions between atoms are determined solely from their electronic configurations and position of the atoms. While highly accurate, this method is very expensive and can only realistically be implemented for small sized systems and very short time scales when applied to molecular dynamics. In the semi-empirical methods, various simplifications are used, e.g. only treating the valence electrons explicitly and fitting several parameters to experimental data (or in some cases to data calculated $a b$-initio), which allows them to probe larger system sizes and longer time scales compared to ab-initio methods. Since electrons are considered in semi-empirical and ab-initio approaches, they may be used to investigate processes that involve bond breaking/formation and electronic rearrangement.

The molecular mechanics (MM) approach is used for simulations of very large systems, typically of up to hundreds of thousands of particles. In this approximation, the microscopic state of the system can be determined using only the positions and forces acting on the atoms. The interaction between atoms is modeled using interatomic potentials (force field) derived from either highly accurate $a b$-initio calculations or fitted to experimental data. When applied to MD, the MM approach enables the study of systems in a time scale up to a microsecond. It is possible to calculate thermodynamic and transport properties and to study a wide range of processes, such as interactions of molecules with surfaces, phase transitions, and protein dynamics. For even larger systems, the molecular mechanics approach is further simplified by introducing restrictions to the degree of freedom and treating groups of atoms as contiguous units. This method is referred to as mesoscale modeling, and is very efficient in accessing quite large system sizes and long time scales, at the expense of atomic-scale accuracy. At the largest size and time scale, continuum methods enable one to simulate a wide range of dynamical processes, which can be compared directly to experiments.

The advances on computational methods aimed at the prediction and understanding of falcipain structures, enzyme-inhibitor interactions, enzyme mechanism and inhibitors reactivity are summarized below and organized according to the technique used in the reviewed studies.

\subsection{Homology Modeling}

The lack of an experimentally determined structure of a target protein frequently limits the application of structure-based drug design methods. X-ray crystallography continues to be an important source of high-resolution information on protein 3D structure. Unfortunately, there is often a considerable delay between determining the sequence of a protein and solving its $3 \mathrm{D}$ structure. Such delay is generally associated to difficulties in protein expression and, more commonly, in protein crystallization. In the absence of such crystal structures, sequence-based homology modeling is a well accepted alternative to derive tridimensional information for use in structurebased drug design [110]. It was found that the performance of the homology model-based docking is comparable to that of the crystal structure-based docking, as long as sequence homology between 
target and model proteins, in the binding site area, is over $50 \%$ [111].

Though the primary sequence of falcipains has been known for eight years, it was only four years ago that the first crystallographic structure was solved. In between, homology modeling was used as an important tool to derive falcipain 3D structures. Homology models of FP2 and FP3 were derived based on multiple sequence alignment (Fig. 10) of these enzymes sequence with homologs, such as the cysteine protease from Trypanosoma cruzi (cruzain) and the cysteine protease from Leishmania donovani, sharing more than $40 \%$ homology in the mature domain and about $90 \%$ for the binding site residues [80, 95]. The rational structures of FP2 and FP3 were developed by several groups [26, 89, 112, 113], validated by various structure/geometry verification tools, docking studies and site-directed mutagenesis and used in subsequent structured-based drug design studies.

So far, six $P$. falciparum cysteine protease structures have been deposited in the Protein Data Bank. One of the structures (PDB code: 2GHU [114]) corresponds to the free FP2, three others contain FP2 in complex with cystatin, chagasin and epoxysuccinate E64 (PDB codes: 1YVB [92], 2OUL [115] and 3BPF [116], respectively) and the two remaining experimental structures represent FP3 in complex with aldehyde leupeptin and K11017, a known potent vinyl sulfone inhibitor (PDB codes: 3BPM [116] and 3BWK [117], respectively).

As mentioned above, falcipains possess two unique structural features: a "nose-like" projection connecting the $\mathrm{L}$ and $\mathrm{R}$ domains and an "arm-like" structure extending away from the protease surface (Fig. 4). FP $_{\text {nose }}$ was found to be essential for the correct folding of the protein and subsequent gain of catalytic activity while $\mathrm{FP}_{\mathrm{arm}}$ is required for hemoglobinase activity. These two motifs were already observed in the rational falcipain models but modeling analyses of those structures did not identify mechanistic or functional roles for these sequence motifs because of the uncertainties in their conformations [89, 113]. However, structural analyses of the first FP2 experimental structure [92] revealed that FP2 $2_{\text {nose }}$ has, in fact, a short but significant element of secondary structure, and that a residue in the protein core (GLU120) forms a buried hydrogen bond with TYR13 and a salt bridge with ARG5, two residues from FP $2_{\text {nose }}$. These interactions may provide the additional binding energy necessary to stabilize initial interactions for folding. $\mathrm{FP}_{\text {arm }}$, the second element unique to the FPs, is a jutting arm-like structure of two extended beta strands connected by an abrupt turn. Structural analysis found a negative charge clustering surrounding $\mathrm{FP}_{\mathrm{arm}}$ and that the majority of this unique motif is distantly located from the active site. This suggests that $\mathrm{FP}_{\text {arm }}$ participates in hemoglobin degradation through distal-site binding rather than direct participation in substrate cleavage.

Despite the publication of the experimental structures for FP2 and FP3, homology modeling remains a valuable tool for studies of the pro-domain of these enzymes. One of the common features that falcipains share with other papain-family cysteine proteases includes a prodomain with potent enzyme activity. Thus, several researchers are interested in evaluating the features of FPs prodomain that mediate enzyme inhibition $[118,119]$. However, the only experimental structures available for FPs are related to the mature proteolytic enzyme. So, models have to be constructed, in order to obtain structural information relative to the prodomain.

Pandey, K. C. et al. [119] constructed a structure model of proFP2 by homology modeling based on crystallographic structures of mature FP2, procathepsin-K, procathepsin-L and procaricain, offering insights into the nature of the interaction between the prodomain and mature domain of FP2 as well as into the broad specificity of inhibitory activity of the FP2 prodomain. They hypothesized that the inhibitory function is mediated by the dowstream portion of the prodomain, which has amino acid sequence similar to that of other

\section{Falcipain2 \\ Falcipain3 \\ Chymopapain (1YAL) \\ GP-II (1CQD) \\ cathepsinK (1ATK)}

Falcipain2
Falcipain3
Chymopapain (1YAL)
GP-II (1CQD)
cathepsinK (1ATK)
Falcipain2
Falcipain3
Chymopapain (1YAL)
GP-II (1CQD)
cathepsinK (1ATK)
Falcipain2
Falcipain3
Chymopapain (1YAL)
GP-II (1CQD)
cathepsinK (1ATK)
Falcipain2
Falcipain3
Chymopapain (1YAL)
GP-II (1CQD)
cathepsinK (1ATK)

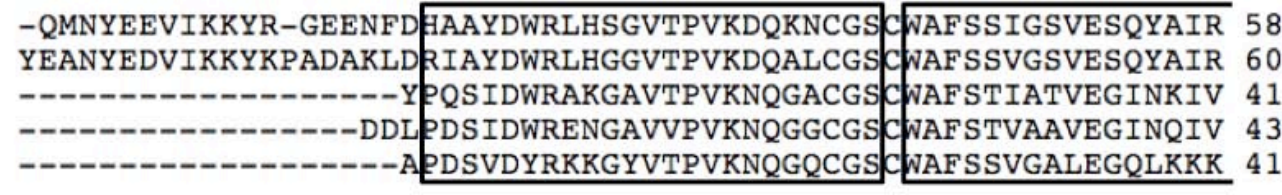

KNKLITLSEQELVDCSFKNYGCNGGLINNAFEDMIELGGICPDGDYPYVSp APNLCNIDR 118 KKALFLFSEQELVDCSVKNNGCYGGYITNAFDDMIDLGGLCSQDDYPYVSNEPETCNLKR 120 TGNLLELSEQELVDCDKHSYGCKGGYQTTSLQYVANN-GVHTSKVYPYQA XYYKCRA TDK 100 TGDLISLSEQQLVDCTTANHGCRGGWMNPAFQFIVNNGGINSEETYPYRGODGICNSTVN 103 TGKLLNLSPQNLVDCVSENDGCGGGYMTNAFQYVOKNR GIDSEDAYPYVGQEESCMYNPT 101

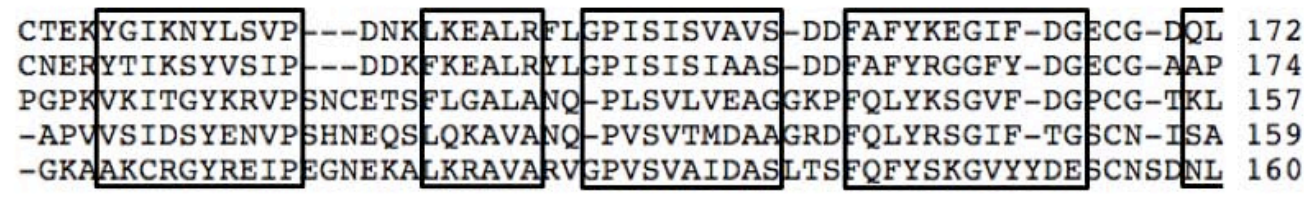

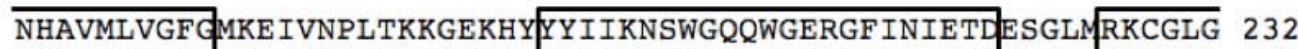
NHAVILVGYGMKDIYNEDTGRMEKFYYYIIKNSWGSDWGEGGYINLETDENGYKKTCSIG 234 DHAVTAVGY TSDGKN-------YIIIKNSWGPNWGEKGYMRLKROSGNSOGTCGVY 207 NHALTVVGY TENDKD--------- FWIVKNSWGKNWGESGYIRAERN IENPDGKCGIT 209 NHAVLAVGYGIQKGNK--------- HWIIKNSWGENWGNKGYILMARNKNN--ACGIA 207

\begin{tabular}{lr}
\hline TDAFIPLIE--- & 241 \\
TEAYVPLIE--- & 243 \\
KSSYYPFKGFA- & 218 \\
RFASYPVKKGTN & 221 \\
NLASFPKM --- & 215 \\
\hline
\end{tabular}

Fig. (10). Sequence alignments of falcipain-2 and falcipain-3 with some homologs of the cysteine protease family used in homology modeling studies. Residues inside boxes represent the structurally conserved regions. Text within parentheses corresponds to the PDB code of the protein. Only the mature sequence of falcipains is presented here. Adapted from [26]. 


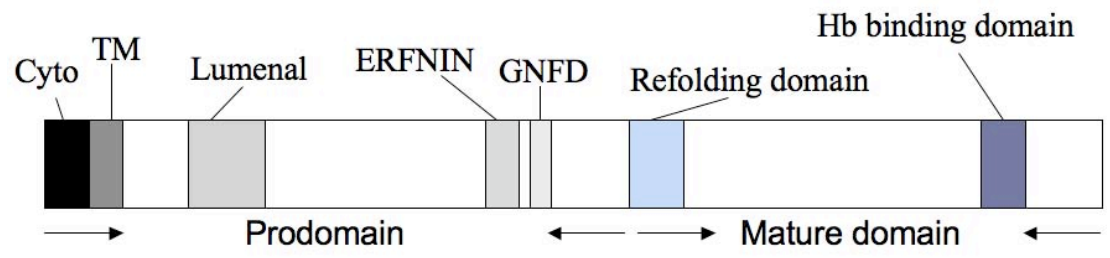

Fig. (11). Schematic representation of the domains of falcipains. Cyto: cytolsolic domain; TM: transmembrane domain; Hb: hemoglobin. ERFNIN and GNFD represent the one-letter code of the peptide sequence. Adapted from [119].

papain family proteases. These two conserved regions correspond to a sequence of 6 (ERFNIN) and 4 (GNFD) amino acids (Fig. 11).

The pro-FP2 model identified potential interactions between the inhibitory portion of the prodomain and mature falcipain- 2 that stabilize the overall fold and appear to explain inhibitory activity. Such interactions correspond to: i) a salt-bridge between ARG185 and GLU121, ii) another salt-bridge between GLU210 (from GNFD) and LYS403 in the mature domain, iii) apolar contacts and $\pi$-bond stacking between PHE214 with TRP449 and TRP453 on the mature domain

\subsection{Docking Studies}

The goal of most molecular docking methods is to predict the binding mode of a small molecule to a macromolecular receptor. The docking problem can be split into two different components. These are the generation of conformations (searching algorithms) of the receptor-ligand complex and scoring function to discriminate between the correct and wrong binding poses [120]. The ensemble of generated conformations must be sufficiently large to contain the best structure that represents the receptor-ligand complex and the scoring function should be able to assign the best score to this conformation. Examples of available docking programs are GOLD [121, 122], GLIDE [123, 124], DOCK [125], and AutoDock [126].

When the 3D structure of a drug target is available, docking methods have two main applications: i) virtual High Throughput Screening (vHTS) and ii) structural information. vHTS consists in the use of docking methods to screen compound libraries in silico to rank the compounds regarding their binding affinities to the target receptor and, ultimately, get the so-called hit(s), i.e., predictably high-affinity compound(s). This way, the huge costs and time consumptions associated to lead discovery by conventional experimental ("wet") High Throughput Screening can be dramatically reduced. Besides, the structural information from the theoretically modeled complex may help to clarify the catalytic mechanism of enzyme and to tailor novel highly potent enzyme inhibitors. As stated above, in recent years, researchers are devoting many efforts in searching FPs inhibitors, but not all structures of inhibitor(s)FP(s) complexes are available. So, to understand the interaction mode between inhibitors and FPs, knowledge about the structures of the complexes is a necessary condition that can be reached with docking methods.

\subsubsection{Virtual Screening}

We have seen that the majority of FPs inhibitors correspond to peptide-based or peptidomimetic compounds. However, these compounds are subjected to metabolic degradation. Thus, it would be of great interest to discover non-peptide inhibitors, which are less exposed to degradation by host proteases and, thereby, more likely to offer in vivo activity. One of the strategies to search for such compounds is the use of virtual screening, which has emerged as a powerful tool for identification of novel and diverse leads [127, 128]. Relative to the discovery of falcipain inhibitors, three virtual screening studies should be highlighted.

Two of them were made by Desai, P.V. et al. who used models of FP2 and FP3 issued from homology modeling to screen the
ChemBridge Database [129] and the Available Chemical Directory [130] with 241000 and 355000 compounds, respectively. Firstly, the databases were filtered to collect only druglike molecules. Thus, compounds with metals were removed and, in the case of salts, the counterions were stripped and the anions were neutralized. The remaining molecules were then filtered based on ADME parameters, and finally subjected to the Lipinski's rule of five [131]. The filtered ChemBridge Database and the Available Chemical Directory consisted of approximately 60000 and 80000, respectively. After that, the GOLD software [122] was utilized to screen the molecules applying a docking protocol, which was previously established by a docking study carried out with the crystal structure of cruzain and a vinyl sulfone inhibitor.

The top 200 common hits for the two FPs were inspected based on several criteria: i) reasonable internal energy of the ligand in the binding pose, ii) proximity of the electrophilic center of the ligand (if any present) to the catalytic cysteine and iii) complementary between the ligand and protein surfaces in terms of spatial occupancy and hydrophilic/hydrophobic regions. In the case of the ChemBridge Database, 22 compounds appeared to inhibit either or both of the enzymes with $\mathrm{IC}_{50}$ values ranging from 1 to $63 \mu \mathrm{M}$, with 12 compounds showing dual activity. Relative to the Available Chemical Directory, 18 compounds were found to be low micromolar inhibitors of FP2 and/or FP3 and, among these molecules, seven showed to have dual activity. All of the ligands seemed to have reasonable interactions and shape complementarity to the active site of the enzyme. Six of the most active compounds issued from these studies are summarized in Table 2.

Despite all selected compounds appeared to span the four major subsites of the binding pockets, S1, S1', S2 and S3, subtle differences could be observed in specific interactions. The analysis of the docked binding conformation of compound 2 (Table 2) revealed that the molecule forms strong van der Waals (vdW) interactions with the binding pocket residues and $\pi-\pi$ stacking interactions with TRP206 in the S1' pocket. Additionally, the carboxylate groups of the inhibitor accept $\mathrm{H}$ bonds from the backbone amide proton of ILE85 in the S2 pocket.

Although most other inhibitors also appeared to form one or more $\mathrm{H}$ bonds with the S1' cavity residues, other molecules showed additional interactions with the S3 pocket, but other significant interactions with the $\mathrm{S} 1$ ' pocket were not found. On the other hand, some compounds showed to have fewer interactions with the S3 pocket than those with the S1 cavity. But, in the end, all ligands presenting good activity against FP2 and/or FP3 seemed to have reasonable interactions with the $\mathrm{S} 2$ pocket, which are thought to be major determinants of specificity for this class of cysteine proteases [130].

The third virtual screening study reported so far was performed by $\mathrm{Li}, \mathrm{H}$. et al. being the first published example where a crystal structure of FP2 was used for virtual screening [132]. Indeed, the experimental structure (PDB code: $2 \mathrm{GHU}$ ) was employed to search the SPECS database (http://www.specs.net) for novel nonpeptidic FP2 inhibitors. Since different docking programs with various scoring functions are known to emphasize different aspects of ligands, 
Table 2. Inhibitory Activities of some Compounds Issued from Virtual Screening Against FP2 and FP3

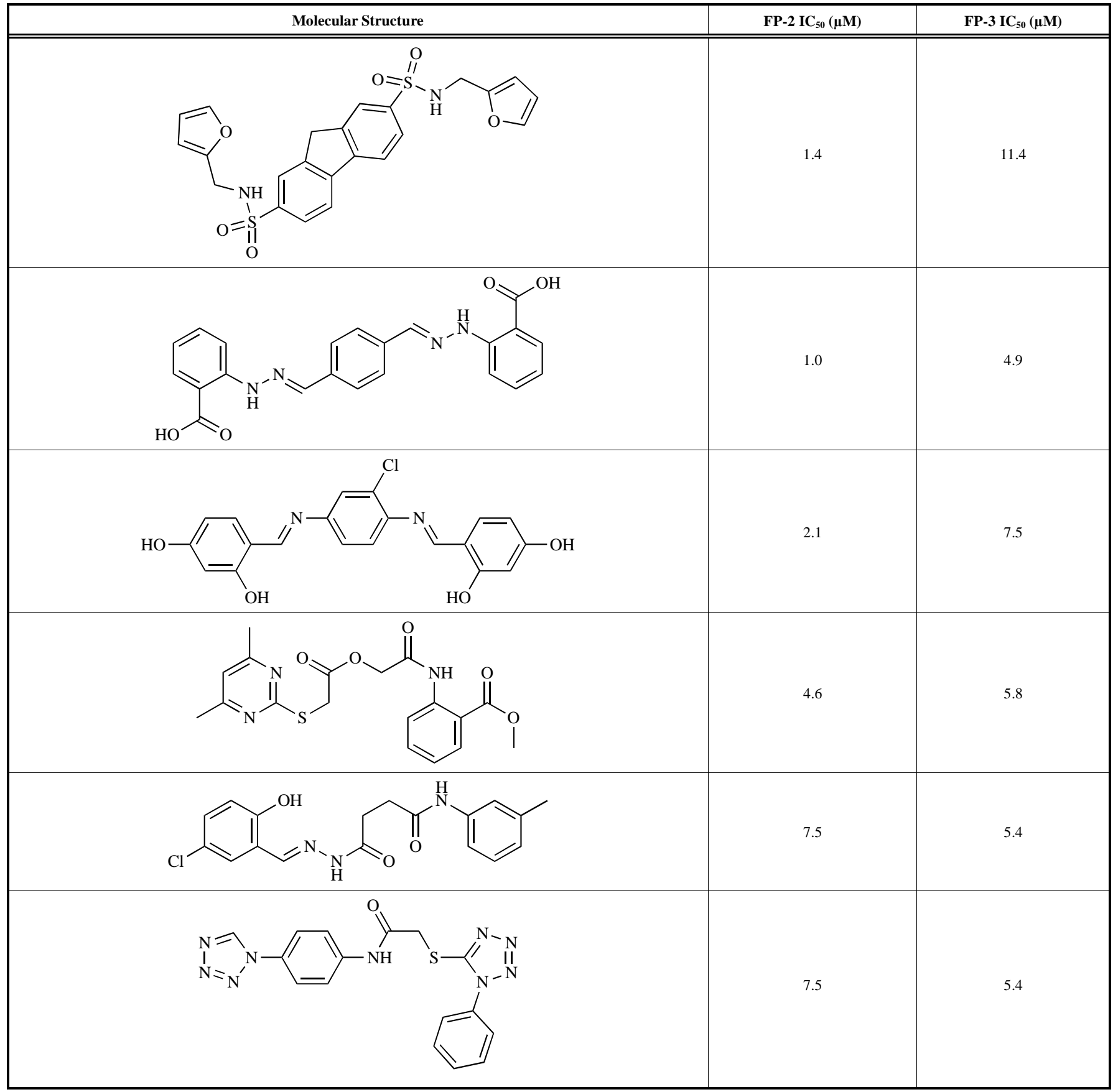

the authors opted to screen the database with two different docking softwares: Glide [124] and GAsDock [133].

The almost 278000 compounds in the SPECS database were reduced, after applying a druglike filter, to about 80000 , which were subsequently ranked and docked with the two docking programs. After visual inspection of the top 200 molecules obtained with each program, 53 and 56 compounds were finally selected by Glide and GAsDock, respectively. From these final molecules only one was common to the two docking programs, which confirmed that different scoring functions indeed emphasize different aspects of ligands. Table 3 registers the three most active compounds reported from this work.

The predicted binding poses of the inhibitors revealed that most of them span and occupy the S2 and S1' pockets with no significant interactions with the S1 cavity. It was also observed that the selected inhibitors form mostly $\mathrm{vdW}$ and hydrophobic interactions with GLY83, ILE85 and ALA235 (in S2 cavity) and, in particular, with VAL152 (in S1' subsite), which can explain why additional lipophilic substituents seem to give better occupancy. In addition, the authors found that some compounds established $\pi-\pi$ stacking interactions between their aromatic systems and TRP206, in the S1' pocket, which appeared to be a necessary feature for good activity. Finally, it was pointed out that the central saddle linker, which connects compound moieties binding to $\mathrm{S} 2$ and $\mathrm{S} 1$ ' pockets, tend to form $\mathrm{H}$ bonds with the polar residues around the active site, such as ASN173, HIS172 and TRP206.

It should be noted that the inhibitors identified by virtual screening have generally $\mathrm{IC}_{50}$ values in the micromolar range, and thus may not be suitable for use as drugs themselves but constitute 
Table 3. Inhibitories Activities of some Compounds Issued from a Virtual Screening Study Against FP2

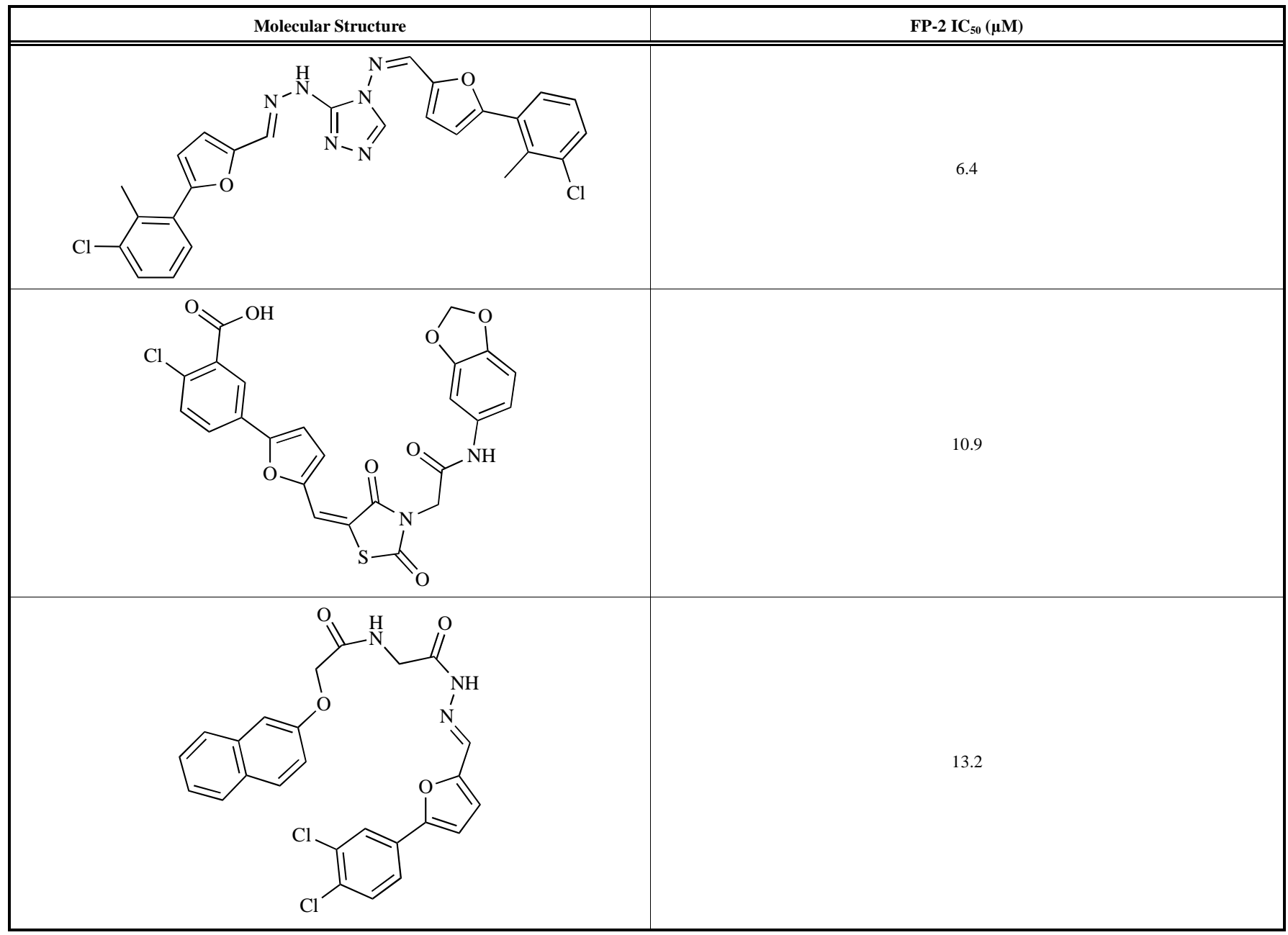

novel and diverse lead structures that should be pursued in lead optimization studies.

\subsubsection{Structural and Functional Properties of Falcipain-Inhibitor Complexes}

As mentioned above, the docking technique also serves to retrieve structural information from the theoretically modeled complexes when these are not available experimentally. These studies represent the major theoretical works developed for falcipains inhibitors and some of them are reviewed below.

One of the first studies that applied structure-based drug design methods to falcipain inhibitors development was entailed by Ring, C.S., et al. [112]. After identifying oxalic bis[(2-hydroxy-1-naphthylmethylene)hydrazide] (Fig. 12) as a nonpeptidic inhibitor of the malarial cysteine protease, the analysis of the docking-generated enzyme-inhibitor complex provided structural information on binding between the molecule and the target receptor. The hydrophobic site S2 was found to be filled by one naphtol group, while the other naphtol group participates in a $\pi-\pi$ stacking interaction with the indole of TRP177 at the S1' pocket. Also, each of the hydroxyl groups in the naphtol rings were seen to establish $\mathrm{H}$ bonds with SER160 and GLN19 at the S2 and S1' cavities, respectively.

Sabnis, Y.A., et al. [26], built a homology model of FP3 and compared it to a previously reported homology model of FP2. The results of this study showed that, despite the active site of the two cysteine proteases is generally conserved, significant differences observed might lead to diverse ligand specificity. Some major alterations in the S2 pocket were detected such as two leucine amino acids in FP2, LEU84 and LEU172, that are replaced by TYR86 and PRO174, respectively, in FP3. These bulkier tyrosine and proline residues in FP3 induce an important steric difference between S2 cavities, which lead to a narrower S2 pocket in FP3 and could explain trends of lower experimentally inhibitory activities of various substrates with FP3, as compared to FP2 [80]. In order to find if this difference could significantly affect ligand interactions, the authors compared the best docking mode of Z-Phe-Arg-AMC (Fig. 13) with the two cysteinases.<smiles>O=C(N/N=C/c1c(O)ccc2ccccc12)C(=O)N/N=C/c1c(O)ccc2ccccc12</smiles>

Oxalic bis[2-hydroxy-1-naphtylmethylene)hydrazide]

Fig. (12). Molecular structure of oxalic bis[(2-hydroxy-1-naphthylmethylene)hydrazide].

They noticed that the compound binds to the enzymes in a similar conformation, with the distance between sulphur of catalytic CYS and the point of cleavage of the substrate (carbonyl carbon of arginine) in the range of 3-4 A. However, the position of the benzyloxycarbonyl group $(\mathrm{Z})$ was found to be different in the two falcipains. In FP2, this group fits into the $S 2$ pocket along with the phenyl group, whereas in FP3 it is dislocated away from the center of the S2 cavity. This displacement appeared to be mainly due to the narrower S2 pocket of FP3. 
<smiles>Cc1cc(=O)oc2cc(NC(=O)[C@H](CCCNC(=N)N)NC(=O)[C@H](Cc3ccccc3)NC(=O)OCc3ccccc3)ccc12</smiles>

Z-Phe-Arg-AMC

Fig. (13). Molecular structure of N- $\alpha$-benzyloxycarbonyl-L-phenylalanyl-Larginine-7-amino-4-methylcoumarin (Z-Phe-Arg-AMC).

In another study performed by Batra, S., et al. [96], a homology model of FP2 was used to design a new nonpeptidic inhibitor having an isoquinoline motif (Fig. 14a). Chemical synthesis and assay for inhibition of the cysteine protease revealed this molecule to be active in the $\mu \mathrm{M}$ range. The interaction established between the 1(4-hydroxy-phenyl) group of the ligand and ASP234 in the S2 pocket was considered essential. Therefore, in order to discover new antimalarial agents, the authors decided to synthesize and evaluate simpler 1,6,7-trisubstituted isoquinoline analogues (Fig. 14b). The analysis of the inhibitor-enzyme complexes issued from docking suggested that the S2 pocket prefers to accommodate hydrophobic groups, since more and stronger interactions were found for molecules bearing the $p$-benzyloxy phenyl group, as compared to their corresponding hydroxyl analogues.<smiles>Oc1ccc(-c2nccc3ccc(Cc4ccccc4)cc23)cc1</smiles><smiles>[R]C=Cc1cccc2ccnc(-c3ccc([R])cc3)c12</smiles>

Fig. (14). Representative structure of a) isoquinoline motif and b) 1,6,7trisubstituted isoquinoline analogues.

In a work of Goh L. L. and co-workers [82, 89], computational approaches, such as sequence alignment and homology modeling of FP2, were used to identify clusters of residues unique to the parasite protease that can be targeted for drug design. In addition to the catalytic triad, (CYS42, HIS174 and ASN204 in FP2) the residues SER149, ILE85, ALA151, ASP155, CYS99 and CYS119 were found to be strictly conserved between FPs when compared to human cathepsins. Thus, these differences in substrate binding sites may be exploited to the drug design of specific falcipain inhibitors. Structural analysis showed that SER149, ILE85, ALA151 and ASP155 do not participate directly in the catalytic reaction, but enhance substrate bond alignment with the catalytic amino acids. This was confirmed by site-directed mutagenesis, since removal of the serine side chain hydroxyl (S149A mutant) resulted in significant loss of proteolytic activity against some peptide substrates. Likewise, simultaneous substitution of the neighboring amino acids ILE85 and ALA151 presented an additive effect over the single mutant and rendered the double mutants completely inactive against the peptide substrates. These three residues were observed to be located in the hydrophobic cleft of the active center, suggesting that they may play important roles in substrate binding and specificity, namely establishing hydrophobic interactions with peptide substrates. On the other hand, ASP155 was shown to be less essential for substrate recognition/binding since the mutant D155A displayed a $50 \%$ decrease in activity relative to the wild-type enzyme. Regarding amino acids CYS99 and CYS119, these residues were found to be absent in the human cysteinase analogues. Although observation of the homology model of FP2 revealed that these CYS residues do not form part of the active site, their conserved nature in FPs suggests that they have an important role. Structural analysis showed that the conformational modifications that these amino acids induce at the protease amino-terminal segment indirectly influence the folding of FP2 and, consequently, the active conformation of the protease.

The homology structures of FP2 and FP3 were also used in the structure-based design of novel trialkyl-substituted thiazoles performed by Goud, P. M., et al. [134]. The authors chose the thiazole ring as core in this series because of the resulting spatial arrangement of the three alkyl groups, which is thought to allow the formation of key interactions with the amino acids in the active site (Fig. 15). The fact that the thiazole ring is bioavailable and, as previously reported, that it mimics the amino acid portion of a peptide bond if held in a planar arrangement, also motivated the authors to select this heterocycle as a common motif for this family of FP nonpeptide inhibitors [134].
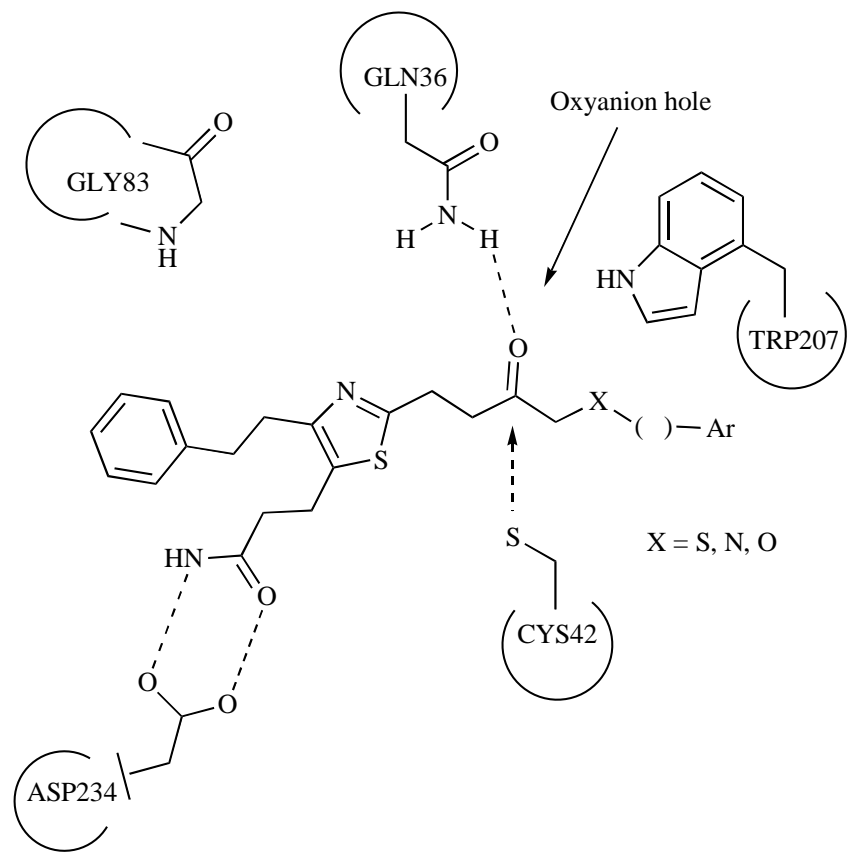

Fig. (15). Proposed schematic representation of important interactions between designed thiazole inhibitors and falcipain amino acids. Hydrogen bonds are shown in dotted lines. Residues are numbered for FP2. Adapted from [134].

From this modeling study resulted a series of thiazole analogues conceived in order to mimic important interactions exhibited by known inhibitors (Fig. 15), and which were docked into the model structures of FP2 and FP3. Some representative structures of the designed thiazoles are shown in Fig. (16).

The binding mode of the designed thiazoles showed that they are able to form a tetrahedral intermediate with CYS42 and to establish $\mathrm{H}$ bonds with key catalytic residues of the enzyme. The $\mathrm{COCH}_{2} \mathrm{X}$ group of the inhibitors interacts with the thiolate/ imidazolium ion pair of FPs wherein the carbonyl oxygen of the compounds is involved in $\mathrm{H}$ bonds with the amide proton of the cata- 

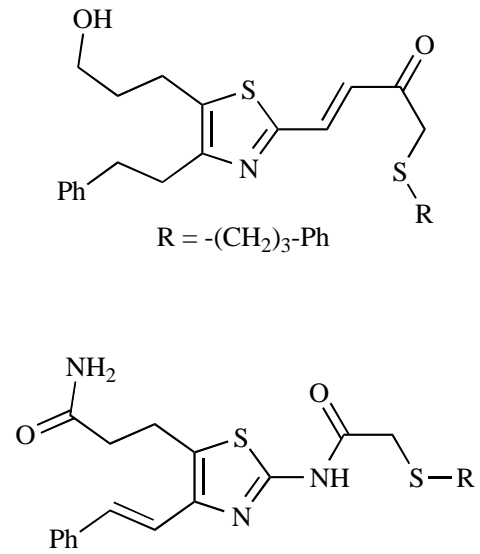<smiles>[R]SCC(=O)CCc1nc(CCc2ccccc2)c(CCC=O)s1</smiles><smiles>[R]SCC(=O)CCc1nc(CO)c(CCc2ccccc2)s1</smiles>
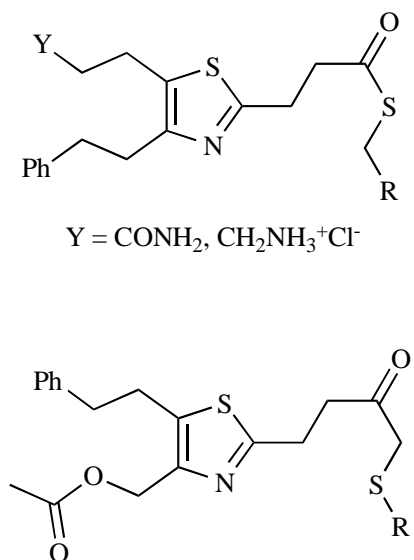

Fig. (16). Representative structure of designed thiazole derivatives as FP inhibitors.

lytic cysteine, and with the side chain amide protons of GLN36 in the oxyanion hole. The phenyl group interacts with the S3 pocket mainly by hydrophobic contacts. Moreover, the side chain hydroxyl or the amide protons at position 4 or 5 of the thiazole ring appear to form a $\mathrm{H}$ bond with either the ASP234 side chain or SER149 in the S2 cavity.

More recently, another modeling study was performed by Veríssimo, E. et al. [107], who derived falcipain inhibitors presenting a non-peptidic scaffold that could constrain the amino acid backbone. This way, the molecules would have some advantages, such as improved selectivity by stabilizing a biologically active conformation and consequent decreased toxicity to the human host. Several molecules presenting a common 2-pyridone motif (Fig. 17), different P1 fragments for recognition and binding to the enzyme, and different Michael acceptor groups capable of reacting with the thiolate of cysteine residue, were designed, synthesized and evaluated for their inhibitory activity against falcipains.

$$
\begin{aligned}
& \mathrm{R}_{1}=\mathrm{CH}_{2} \mathrm{Ph}, \mathrm{C}_{2} \mathrm{H}_{4} \mathrm{Ph} \\
& \mathrm{R}_{2}=\mathrm{CHO}, \mathrm{CH}_{2} \mathrm{CHCOOMe}, \mathrm{CH}_{2} \mathrm{CHSO}_{2} \mathrm{Ph}
\end{aligned}
$$

Fig. (17). Molecular structure of 2-pyridone derivatives.

The results confirmed that $\mathrm{P} 1$ recognition sites of FP2 inhibitors exhibiting longer chain substituents performed much better. Despite modeling studies showed good matches between peptidomimetic conformations and their peptidic counterparts, antimalarial activity is more significant in the case of the vinyl sulfone analogues, suggesting that the electrophilic moiety of the latter is very reactive towards the nucleophilic thiolate group of FPs.

\subsection{Molecular Dynamics}

As mentioned above, MD is a statistical mechanics method in which the time evolution of interacting atoms is followed by integrating their equations of motion. Classical MD relies on Molecular Mechanics (MM) to simulate the deformations, movements and interactions of molecules, which in turn allow the calculation of energetic, thermodynamic, structural and dynamic properties as well as conformational searches.

Cieplak, P. and co-workers [135] performed one of the first and few MD studies on model complexes of FPs inhibitors. In their work, classical MD was used as a filter for evaluating proposed binding modes. In addition, they calculated free energy derivatives at each atom of the molecules. From their results it was possible to suggest which atomic regions should have larger or smaller van der Waals radii, larger or smaller van der Waals well depths and larger or smaller partial charges. This computational approach was applied to three compounds (Fig. 18). The first compound, oxalic-bis-(2hydroxy-1-naphtylmethylene)-hydrazide, was issued from a virtual screening study. The second molecule was obtained from the latter by introducing a shorter linker between the aromatic rings, in order to have the ability to move more freely along the enzymatic side of the protein. Finally, the third species selected for the test was ZLIV114A, the best tri-aryl inhibitor found in a screening previously performed by Li, Z., et al. [136].

After minimization, equilibration and $100 \mathrm{ps}$ of MD production, all molecules were found to be close to their initial docked positions, with largest atomic displacements found to be $\sim 4 \AA$. Importantly, the electrostatic contribution of the free energy derivatives suggested that binding improvements to the enzyme should be based on the increment of both size and electropositive character of the aryl ring located close to the S2 subsite, whereas binding to the cysteine protease should be focused in the insertion of more electronegative groups into the aryl ring positioned in the S1' pocket.

\subsection{Quantum Mechanical Methods}

Although not directly resulting in new inhibitors, quantum mechanics (QM) and/or combined quantum mechanics / molecular mechanics $(\mathrm{QM} / \mathrm{MM})$ methods have given important insights into the catalytic mechanism of falcipains and into the falcipain inhibitors reactivity. QM approaches are mandatory for the computation of bond-breaking or bond-forming processes but, on the other hand, large systems such as protein-ligand complexes would be prohibitively expensive - in terms of computational resources - if fully treated by quantum mechanics. Therefore, combined QM/MM methods are frequently used to treat, at different levels of calculation, various regions of the systems under study.

Concerning the application of $\mathrm{QM}$ or $\mathrm{QM} / \mathrm{MM}$ approaches to the scrutiny of FPs inhibitors, many examples are focused on epoxides and aziridines [137-141].

Kinetics, thermodynamics and regioselectivity of the ringopening reaction of epoxide- and aziridine-based agents (Fig. 19) has been investigated by QM calculations [138, 139]. Generally, the mode of action of these molecules is described as a two-step mechanism. Firstly, there is a formation of a non-convalent enzyme-inhibitor complex assured by a favorable arrangement of the molecule into the binding pocket. Then, ring opening (Fig. 20) takes place, when one of the carbon atoms of the ring is attacked by the thiolate group of the catalytic CYS, which leads to irreversible alkylation of this amino acid. 


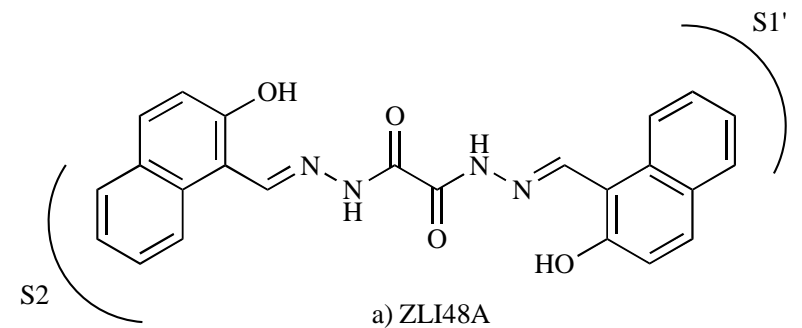<smiles>CCc1ccccc1/C=N/NC(=O)c1cc2ccccc2cc1O</smiles>

b) ZLI93<smiles>CC(C)(C)C(C)(C)C</smiles>

Fig. (18). Molecular structure of a) ZLI48A, b) ZLI93 and c) ZLIV114A.
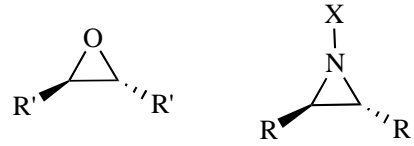

Fig. (19). General structure of (a) epoxide- and (b) aziridine-based inhibitors.

The quantum chemical calculations predicted that protonation of the nitrogen center of aziridine-based inhibitors occurs at the beginning of the reaction course, more precisely, prior to the transition state for the ring opening described above. Importantly, it was found also that, without such previous $\mathrm{N}$-protonation step, the aziridine is not active. Therefore, it is suggested that the protonation stabilizes both the transition state and the product of ring opening, significantly increasing the reaction rate. Hence, electronwithdrawing substituents at the nitrogen atom should lead to lower reaction barriers and, consequently, to higher inhibition potencies. For epoxide-based inhibitors, the protonation of the oxygen center takes place only after occurrence of the transition state; therefore, since the products are strongly stabilized, only the thermodynamics of this reaction is favored by the $O$-protonation, while the kinetics remains unchanged, in contrast with the behavior of aziridines.

Keeping in mind that $N$-substituted aziridine-based derivatives are more potent than the corresponding $N$-unsubstituted analogues, Buback, V. et al. focused on the $N$-substitution pattern by varying the electron-withdrawing power of substituents like $\mathrm{CHO}, \mathrm{Cl}, \mathrm{Br}$, $\mathrm{CF}_{3}, \mathrm{CF}_{2} \mathrm{H}$ and $\mathrm{C}_{6} \mathrm{H}_{4} \mathrm{NO}_{2}$ [137]. Insights into the kinetics and ther- modynamics of ring opening were obtained for the different $\mathrm{N}$ substituted aziridines (Fig. 21), through the achievement of twodimensional potential energy surfaces, and compared with the corresponding non-substituted analogues. The computed reaction barriers for the substituted aziridines ranged from $13-16 \mathrm{kcal} \cdot \mathrm{mol}^{-1}$, representing a decrease in the activation barriers of up to 15 $\mathrm{kcal} \cdot \mathrm{mol}^{-1}$, as compared to the unsubstituted compounds, supporting the correlation between compound activity and the presence of such groups attached to the $\mathrm{N}$ atom.

Relevantly, this study provided further evidence that the inhibitory activity of the tested heterocyclic molecules is also due to a nucleophilic attack of the CYS thiolate to an electron-deficient carbon of the inhibitor, in this particular case involving concomitant opening of the inhibitor's ring structure. The only exception was observed for $N$-formyl-aziridines, which display other reaction pathways (e.g., attack at the carbonyl carbon) that may be involved in the inhibition mechanism as already reported in a previous work [141].

In another example, QM/MM methods were applied to investigate the importance of the HIS residue present at the FPs active site for the activity of epoxide- or aziridine-based cysteine proteases inhibitors [140]. The results excluded a direct proton shift from HIS to the organic ligand, showing instead that a single water molecule is sufficient to establish a very efficient relay system, which turns easier the proton transfer from HIS to the inhibitor. This finding strongly suggests that substituents susceptible to block the proton transfer might diminish the activity of the inhibitors.

Regarding the use of semi-empirical methods in the study of potential FPs inhibitors, Sant'Anna et al. performed calculations on
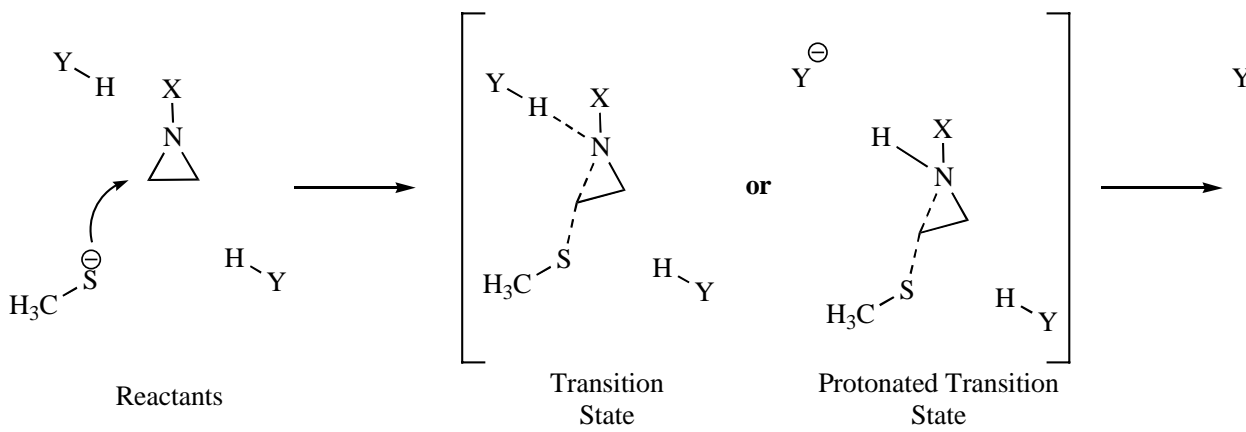

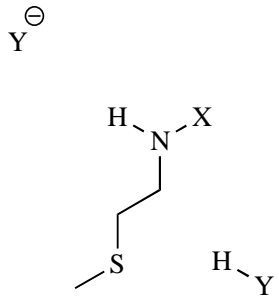

Products

Fig. (20). Schematic representation of the ring opening mechanism of the alkylation of a methyl thiolate by an N-substituted aziridine ring. Adapted from [137]. 
a series of acylhydrazones (Fig. 22) at the AM1 level [142]. These acylhydrazones, which were found to inhibit cysteinases at the $\mathrm{nM}$ level, resulted from lead optimization studies based on the oxalic bis[(2-hydroxy-1-naphtylmethylene)hydrazide] originally reported by Ring and co-workers [112].

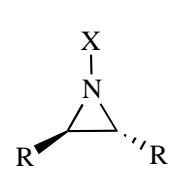

$\mathrm{CHO}, \mathrm{H}, \mathrm{Cl}, \mathrm{Br}, \mathrm{CF}_{3}$, $\mathrm{CF}_{2} \mathrm{H}, \mathrm{C}_{6} \mathrm{H}_{4} \mathrm{NO}_{2}$, $\mathrm{CF}_{2} \mathrm{CO}_{2} \mathrm{Et}, \mathrm{CH}_{2} \mathrm{CO}_{2} \mathrm{Et}$

$\mathbf{R}$

$\mathrm{CO}_{2} \mathrm{Et}, \mathrm{H}, \mathrm{CO}_{2} \mathrm{Bn}$

Fig. (21). Molecular structure of $\mathrm{N}$-substituted aziridines.<smiles>[R]c1cc([R4])c(/C=N\NC(=O)c2cnn(-c3ccccc3)c2)c([R])c1[R]</smiles>

$\mathrm{R}_{1}=\mathrm{H}, \mathrm{OMe}$

$\mathrm{R}_{2}=\mathrm{H}, \mathrm{OH}, \mathrm{OMe}, \mathrm{Cl}$

$\mathrm{R}_{3}=\mathrm{H}, \mathrm{OH}, \mathrm{OMe}, \mathrm{Cl}$

$\mathrm{R}_{4}=\mathrm{H}, \mathrm{OH}$

Fig. (22). Molecular structures of pyrazole acylhydrazones.

According to the work by Sant'Anna et al. the AM1-derived heats of formation for the (Z)- and (E)-isomers of the acylhydrazones were found to be very similar. Also, the calculated atomic charges (based on Mulliken populations) suggested that a more positive charge in the amide carbonyl, which is to be attacked by the catalytic CYS, tends to favor the formation of the tetrahedral intermediate.

In addition, the pyrazole ring and the oxygen atom from the hydroxy and/or methoxy moities of the aromatic ring, were found to establish important stabilizing contacts (hydrogen bonds) with the active site amino acids.

Lastly, it should be outlined that QM/MM methods are quite time demanding on both preparing the system and subsequent calculations; therefore, their application in the accurate molecular description of the active site in enzyme-inhibitor complexes is quite limited. Nevertheless, recent advances in computational facilities allow foreseeing that these approaches will turn practical in the near future, hopefully facilitating the accomplishment of atomically detailed mechanistic studies of plasmodial cysteine proteases, as well as the attainment of reactivity insights into other typical FP inhibitor classes such as that of vinyl sulfones.

\section{CONCLUDING REMARKS}

The increasing resistance of Plasmodium parasites to conventional drug therapy, the inexistence of a vaccine and the appearing of insecticide-resistant mosquitoes make malaria a worldwide public health threat. Thus, the existing situation clearly suggests an urgent need for development of new potent, mechanism-based antimalarial agents. During the last two decades, we have witnessed an impressive scientific effort to discover new targets for antimalarial therapy, and among them, the falcipain family proteases, namely FP2 and FP3, have been defined as promising drug targets. In the present review, several molecular modeling tools used in the identification of new falcipain inhibitors and lead optimization were overviewed. One of the major computational approaches employed in the development of FPs inhibitors consists of the establishment of falcipain structures by homology modeling. The availability of such structural information, combined with docking, is likely to increase the success of virtual screening and of structural and functional properties of falcipain-inhibitor complexes. More recently, some mechanistic studies were also reported, which have not resulted directly in the designg of new drugs, but gave important insights into the catalytic mechanism of falcipains and into the reactivity of falcipains inhibitors. In conclusion, the discussed efforts towards the design of inhibitors of the malarial cysteine proteases clearly demonstrate the effectiveness of combining computational techniques with organic synthesis in delivering novel potential inhibitors and in providing directions for further improvements.

\section{ACKNOWLEDGEMENTS}

We are grateful for the financial support from Fundação para a Ciência e a Tecnologia (FCT, Portugal) to CIQ-UP and CICECO, for the Programme Ciência 2007 and for the Post-doctoral fellowship SFRH/BPD/62967/2009 to Cátia Teixeira. We also thank FCT and the European Union (FEDER) for co-funding this Project (refs. PTDC/QUI/65142/2006 and FCOMP-01-0124-FEDER-007418).

\section{REFERENCES}

[1] Cox, F.E. History of the discovery of the malaria parasites and their vectors. Parasit. Vectors. 2010, 3 (1), 5.

[2] Schlagenhauf, P. Malaria: from prehistory to present. Infect. Dis. Clin. North Am., 2004, 18 (2), 189-205.

[3] Laveran, A. Note sur un nouveau parasite trouvé dans le sang de plusieurs malades atteints de fièvre palustre. Bull. Acad. Med., 1888, 2nd Series (9), 1235-1236.

[4] Ross, R. On Some Peculiar Pigmented Cells Found in Two Mosquitoes Fed on Malarial Blood. Br. Med. J., 1897, 2, 1786-1788.

[5] Grassi, B.; Bigmami, A. A Cielo evolutivo delle semilune ell'Anopheles claviger ed altri studie sulla malaria dall'Ottobre 1898 al Maggio 1899. Ann. d'Igien. Sper., 1899, 9, 258-271.

[6] Gilles, H.M.; Lucas, A.O. Tropical medicine: 100 years of progress. Br. Med. Bull., 1998, 54 (2), 269-80.

[7] Sachs, J.; Malaney, P. The economic and social burden of malaria. Nature. 2002, 415 (6872), 680-5.

[8] http://www.who.int/mediacentre/factsheets/fs094/en/index.html. (accessed 21/05/2010).

[9] Tang, T.-H. T.; Salas, A.; Ali-Tammam, M.; Martínez, M.-C.; Lanza, M.; Arroyo, E.; Rubio. J. M. First case of detection of Plasmodium knowlesi in Spain by Real Time PCR in a traveller from Southeast Asia. Malaria J. 2010 , 9, 219.

[10] Alílio, M.S.; Bygbjerg, I.C.; Breman, J.G. Are multilateral Malarial Research and Control Programs the Most Successful? Lessons from the Past 100 Years in Africa. Am. J. Trop. Medicine Hyg., 2004, 71, 268-278.

[11] Richie, T.L.; Saul, A. Progress and challenges for malaria vaccines. Nature. 2002, 415 (6872), 694-701.

[12] Breman, J.G. The Ears of the Hippopotamus: Manifestations, Determinants and Estimates of the Malaria Burden. Am. J. Trop. Medicine Hyg., 2001, 64 $((1,2) \mathrm{S}), 1-11$

[13] Snow, R.W.; Trape, J.F.; Marsh, K. The past, present and future of childhood malaria mortality in Africa. Trends. Parasitol., 2001, 17 (12), 593-7.

[14] Towie, N. Malaria breakthrough raises spectre of drug resistance. Nature. 2006, 440 (7086), 852-3.

[15] White, N.J. Drug resistance in malaria. Br. Med. Bull., 1998, 54 (3), 703-15.

[16] White, N.J. Antimalarial drug resistance. J. Clin. Invest., 2004, 113 (8), 1084-92.

[17] Das, M.K.; Lumb, V.; Mittra, P.; Singh, S.S.; Dash, A.P.; Sharma, Y.D. High chloroquine treatment failure rates and predominance of mutant genotypes associated with chloroquine and antifolate resistance among falciparum malaria patients from the island of Car Nicobar, India. J. Antimicrob. Chemother., 2010, 65 (6), 1258-61.

[18] Martin, R.E.; Kirk, K. The malaria parasite's chloroquine resistance transporter is a member of the drug/metabolite transporter superfamily. Mol. Biol. Evol., 2004, 21 (10), 1938-49.

[19] Wiesner, J.; Ortmann, R.; Jomaa, H.; Schlitzer, M. New antimalarial drugs. Angew. Chem. Int. Ed. Engl., 2003, 42 (43), 5274-93.

[20] Sirawaraporn, W.; Sathitkul, T.; Sirawaraporn, R.; Yuthavong, Y.; Santi, D.V. Antifolate-resistant mutants of Plasmodium falciparum dihydrofolate reductase. Proc. Natl. Acad. Sci. U S A. 1997, 94 (4), 1124-9.

[21] Eckstein-Ludwig, U.; Webb, R.J.; Van Goethem, I.D.; East, J.M.; Lee, A.G.; Kimura, M.; O'Neill, P.M.; Bray, P.G.; Ward, S.A.; Krishna, S. Artemisinin target the SERCA of Plasmodium falciparum. Nature. 2003, 424 (6951), 957-61.

[22] Nandakumar, D.N.; Nagaraj, V.A.; Vathsala, P.G.; Rangarajan, P.; Padmanaban, G. Curcumin-artemisinin combination therapy for malaria. Antimicrob. Agents Chemother., 2006, 50 (5), 1859-60.

[23] Pandey, A.V.; Tekwani, B.L.; Singh, R.L.; Chauhan, V.S. Artemisinin, an endoperoxide antimalarial, disrupts the hemoglobin catabolism and heme 
detoxification systems in malarial parasite. J. Biol. Chem., 1999, 274 (27), 19383-8.

[24] Gardner, M.J.; Hall, N.; Fung, E.; White, O.; Berriman, M.; Hyman, R.W.; Carlton, J.M.; Pain, A.; Nelson, K.E.; Bowman, S.; Paulsen, I.T.; James, K.; Eisen, J.A.; Rutherford, K.; Salzberg, S.L.; Craig, A.; Kyes, S.; Chan, M.S.; Nene, V.; Shallom, S.J.; Suh, B.; Peterson, J.; Angiuoli, S.; Pertea, M.; Allen, J.; Selengut, J.; Haft, D.; Mather, M.W.; Vaidya, A.B.; Martin, D.M.; Fairlamb, A.H.; Fraunholz, M.J.; Roos, D.S.; Ralph, S.A.; McFadden, G.I.; Cummings, L.M.; Subramanian, G.M.; Mungall, C.; Venter, J.C.; Carucci, D.J.; Hoffman, S.L.; Newbold, C.; Davis, R.W.; Fraser, C.M.; Barrell, B. Genome sequence of the human malaria parasite Plasmodium falciparum. Nature. 2002, 419 (6906), 498-511.

[25] Padmanaban, G. Drug targets in malaria parasites. Adv. Biochem. Eng. Biotechnol, 2003, 84, 123-41.

[26] Sabnis, Y.A.; Desai, P.V.; Rosenthal, P.J.; Avery, M.A. Probing the structure of falcipain-3, a cysteine protease from Plasmodium falciparum: comparative protein modeling and docking studies. Protein Sci., 2003, 12 (3), 501-9.

[27] Dua, M.; Raphael, P.; Sijwali, P.S.; Rosenthal, P.J.; Hanspal, M. Recombinant falcipain-2 cleaves erythrocyte membrane ankyrin and protein 4.1. Mol. Biochem. Parasitol., 2001, 116 (1), 95-9.

[28] Rosenthal, P.J. Cysteine proteases of malaria parasites. Int. J. Parasitol., 2004, 34 (13-14), 1489-99.

[29] Shenai, B.R.; Sijwali, P.S.; Singh, A.; Rosenthal, P.J. Characterization of native and recombinant falcipain-2, a principal trophozoite cysteine protease and essential hemoglobinase of Plasmodium falciparum. J. Biol. Chem., 2000, 275 (37), 29000-10.

[30] Khan, S.M.; Waters, A.P. Malaria parasite transmission stages: an update. Trends. Parasitol., 2004, 20 (12), 575-80.

[31] Mueller, I.; Galinski, M.R.; Baird, J.K.; Carlton, J.M.; Kochar, D.K.; Alonso, P.L.; del Portillo, H.A. Key gaps in the knowledge of Plasmodium vivax, a neglected human malaria parasite. Lancet Infect Dis. 2009, 9 (9), 555-66.

[32] Alonso, P.L.; Sacarlal, J.; Aponte, J.J.; Leach, A.; Macete, E.; Milman, J.; Mandomando, I.; Spiessens, B.; Guinovart, C.; Espasa, M.; Bassat, Q.; Aide, P.; Ofori-Anyinam, O.; Navia, M.M.; Corachan, S.; Ceuppens, M.; Dubois, M.C.; Demoitie, M.A.; Dubovsky, F.; Menendez, C.; Tornieporth, N.; Ballou, W.R.; Thompson, R.; Cohen, J. Efficacy of the RTS,S/AS02A vaccine against Plasmodium falciparum infection and disease in young African children: randomised controlled trial. Lancet. 2004, 364 (9443), 1411-20.

[33] Thera, M.A.; Doumbo, O.K; Coulibaly, D; Laurens, M.B; Kone, A.K; Guindo, A.B.; Traore, K.; Sissoko, M.; Diallo, D.A.; Diarra, I.; Kouriba, B.; Daou, M.; Dolo, A.; Baby, M.; Sissoko, M.S.; Sagara, I.; Niangaly, A.; Traore, I.; Olotu, A.; Godeaux, O.; Leach, A.; Dubois, M.C.; Ballou, W.R.; Cohen, J.; Thompson, D.; Dube, T.; Soisson, L.; Diggs, C.L.; Takala, S.L.; Lyke, K.E.; House, B.; Lanar, D.E.; Dutta, S.; Heppner, D.G.; Plowe, C.V. Safety and immunogenicity of an AMA1 malaria vaccine in Malian children: results of a phase 1 randomized controlled trial. PLoS One. 2010, 5 (2), e9041.

[34] Greenwood, B.M.; Bojang, K.; Whitty, C.J.; Targett, G.A. Malaria. Lancet. 2005, 365 (9469), 1487-98.

[35] Baird, J.K. Effectiveness of antimalarial drugs. N. Engl. J. Med., 2005, 352 (15), 1565-77

[36] Chiang, P.K.; Bujnicki, J.M.; Su, X.; Lanar, D.E. Malaria: therapy, genes and vaccines. Curr. Mol. Med., 2006, 6 (3), 309-26.

[37] Hayton, K.; Su, X.Z. Genetic and biochemical aspects of drug resistance in malaria parasites. Curr. Drug Targets Infect. Disord., 2004, 4 (1), 1-10.

[38] Noedl, H.; Se, Y.; Schaecher, K.; Smith, B.L.; Socheat, D.; Fukuda, M.M. Evidence of artemisinin-resistant malaria in western Cambodia. N. Engl. J. Med., 2008, 359 (24), 2619-20.

[39] Noedl, H.; Socheat, D.; Satimai, W. Artemisinin-resistant malaria in Asia. $N$. Engl. J. Med., 2009, 361 (5), 540-1.

[40] Walker, D.J.; Pitsch, J.L.; Peng, M.M.; Robinson, B.L.; Peters, W.; Bhisutthibhan, J.; Meshnick, S.R. Mechanisms of artemisinin resistance in the rodent malaria pathogen Plasmodium yoelii. Antimicrob. Agents Chemother., 2000, 44 (2), 344-7.

[41] Organization, W.H., Guidelines for the treatment of malaria. 2nd ed.; WHO Press: Geneva, 2010; p 211

[42] White, N.J.; Nosten, F.; Looareesuwan, S.; Watkins, W.M.; Marsh, K.; Snow, R.W.; Kokwaro, G.; Ouma, J.; Hien, T.T.; Molyneux, M.E.; Taylor, T.E.; Newbold, C.I.; Ruebush, T.K., 2nd; Danis, M.; Greenwood, B.M.; Anderson, R.M.; Olliaro, P. Averting a malaria disaster. Lancet. 1999, 353 (9168), 1965-7.

[43] Dominguez, J.N. Chemotherapeutic agents against malaria: what next after chloroquine? Curr. Top. Med. Chem., 2002, 2 (11), 1173-85.

[44] Jana, S.; Paliwal, J. Novel molecular targets for antimalarial chemotherapy. Int. J. Antimicrob. Agents. 2007, 30 (1), 4-10.

[45] Rosenthal, P.J. Hydrolysis of erythrocyte proteins by proteases of malaria parasites. Curr. Opin. Hematol., 2002, 9 (2), 140-5.

[46] Roggero, R.; Zufferey, R.; Minca, M.; Richier, E.; Calas, M.; Vial, H.; Ben Mamoun, C. Unraveling the mode of action of the antimalarial choline analog G25 in Plasmodium falciparum and Saccharomyces cerevisiae. Antimicrob. Agents Chemother, 2004, 48 (8), 2816-24.

[47] Nallan, L.; Bauer, K.D.; Bendale, P.; Rivas, K.; Yokoyama, K.; Horney, C.P.; Pendyala, P.R.; Floyd, D.; Lombardo, L.J.; Williams, D.K.; Hamilton,
A.; Sebti, S.; Windsor, W.T; Weber, P.C; Buckner, F.S.; Chakrabarti, D; Gelb, M.H.; Van Voorhis, W.C. Protein farnesyltransferase inhibitors exhibit potent antimalarial activity. J. Med. Chem., 2005, 48 (11), 3704-13.

[48] Jelenska, J.; Crawford, M.J.; Harb, O.S.; Zuther, E.; Haselkorn, R.; Roos, D.S.; Gornicki, P. Subcellular localization of acetyl-CoA carboxylase in the apicomplexan parasite Toxoplasma gondii. Proc. Natl. Acad. Sci. U S A. 2001, 98 (5), 2723-8.

[49] Sharma, S.K.; Kapoor, M.; Ramya, T.N.; Kumar, S.; Kumar, G.; Modak, R. Sharma, S.; Surolia, N.; Surolia, A. Identification, characterization, and inhibition of Plasmodium falciparum beta-hydroxyacyl-acyl carrier protein dehydratase (FabZ). J. Biol. Chem., 2003, 278 (46), 45661-71.

[50] He, X.; Reeve, A.M.; Desai, U.R.; Kellogg, G.E.; Reynolds, K.A. 1,2 dithiole-3-ones as potent inhibitors of the bacterial 3-ketoacyl acyl carrie protein synthase III (FabH). Antimicrob. Agents Chemother, 2004, 48 (8), 3093-102

[51] McLeod, R.; Muench, S.P.; Rafferty, J.B.; Kyle, D.E.; Mui, E.J.; Kirisits, M.J.; Mack, D.G.; Roberts, C.W.; Samuel, B.U.; Lyons, R.E.; Dorris, M.; Milhous, W.K.; Rice, D.W. Triclosan inhibits the growth of Plasmodium falciparum and Toxoplasma gondii by inhibition of apicomplexan Fab I. Int. J. Parasitol., 2001, 31 (2), 109-13.

[52] Ting, L.M.; Shi, W.; Lewandowicz, A.; Singh, V.; Mwakingwe, A.; Birck, M.R.; Ringia, E.A.; Bench, G.; Madrid, D.C.; Tyler, P.C.; Evans, G.B.; Furneaux, R.H.; Schramm, V.L.; Kim, K. Targeting a novel Plasmodium falciparum purine recycling pathway with specific immucillins. J. Biol. Chem., 2005, 280 (10), 9547-54

[53] Srivastava, I.K.; Rottenberg, H.; Vaidya, A.B. Atovaquone, a broad spectrum antiparasitic drug, collapses mitochondrial membrane potential in a malaria parasite. J. Biol. Chem., 1997, 272 (7), 3961-6.

[54] Nzila, A.; Mberu, E.; Bray, P.; Kokwaro, G.; Winstanley, P.; Marsh, K.; Ward, S. Chemosensitization of Plasmodium falciparum by probenecid in vitro. Antimicrob. Agents Chemother, 2003, 47 (7), 2108-12.

[55] Patel, A.P.; Staines, H.M.; Krishna, S. New antimalarial targets: the example of glucose transport. Travel. Med. Infect. Dis., 2008, 6 (1-2), 58-66.

[56] Boss, C.; Richard-Bildstein, S.; Weller, T.; Fischli, W.; Meyer, S.; Binkert, C. Inhibitors of the Plasmodium falciparum parasite aspartic protease plasmepsin II as potential antimalarial agents. Curr. Med. Chem., 2003, 10 (11), 883-907.

[57] Ettari, R.; Bova, F.; Zappala, M.; Grasso, S.; Micale, N. Falcipain-2 inhibitors. Med. Res. Rev., 2010, 30 (1), 136-67.

[58] Kumar, S.; Guha, M.; Choubey, V; Maity, P.; Bandyopadhyay, U. Antimalarial drugs inhibiting hemozoin (beta-hematin) formation: a mechanistic update. Life Sci., 2007, 80 (9), 813-28.

[59] Goldberg, D.E. Hemoglobin degradation in Plasmodium-infected red blood cells. Semin. Cell Biol., 1993, 4 (5), 355-61.

[60] Goldberg, D.E. Hemoglobin degradation. Curr. Top. Microbiol. Immunol., 2005, 295, 275-91

[61] Olson, J.E.; Lee, G.K.; Semenov, A.; Rosenthal, P.J. Antimalarial effects in mice of orally administered peptidyl cysteine protease inhibitors. Bioorg. Med. Chem., 1999, 7 (4), 633-8.

[62] Rosenthal, P.J. Plasmodium falciparum: effects of proteinase inhibitors on globin hydrolysis by cultured malaria parasites. Exp. Parasitol., 1995, 80 (2), 272-81.

[63] Ersmark, K.; Samuelsson, B.; Hallberg, A. Plasmepsins as potential targets for new antimalarial therapy. Med. Res. Rev., 2006, 26 (5), 626-66.

[64] Blackman, M.J. Proteases involved in erythrocyte invasion by the malaria parasite: function and potential as chemotherapeutic targets. Curr. Drug Targets. 2000, $l(1), 59-83$.

[65] Eggleson, K.K.; Duffin, K.L.; Goldberg, D.E. Identification and characterization of falcilysin, a metallopeptidase involved in hemoglobin catabolism within the malaria parasite Plasmodium falciparum. J. Biol. Chem., 1999, 274 (45), 32411-7.

[66] Gluzman, I.Y.; Francis, S.E.; Oksman, A.; Smith, C.E.; Duffin, K.L.; Goldberg, D.E. Order and specificity of the Plasmodium falciparum hemoglobin degradation pathway. J. Clin. Invest., 1994, 93 (4), 1602-8.

[67] Liu, J.; Istvan, E.S.; Gluzman, I.Y.; Gross, J.; Goldberg, D.E. Plasmodium falciparum ensures its amino acid supply with multiple acquisition pathways and redundant proteolytic enzyme systems. Proc. Natl. Acad. Sci. U S A. 2006, 103 (23), 8840-5.

[68] Goldberg, D.E.; Slater, A.F.; Beavis, R . Chait, B.; Cerami, A.; Henderson, G.B. Hemoglobin degradation in the human malaria pathogen Plasmodium falciparum: a catabolic pathway initiated by a specific aspartic protease. $J$. Exp. Med., 1991, 173 (4), 961-9.

[69] Francis, S.E.; Sullivan, D.J., Jr.; Goldberg, D.E. Hemoglobin metabolism in the malaria parasite Plasmodium falciparum. Annu. Rev. Microbiol., 1997, 51, 97-123.

[70] Klemba, M.; Gluzman, I.; Goldberg, D.E. A Plasmodium falciparum dipeptidyl aminopeptidase I participates in vacuolar hemoglobin degradation. J. Biol. Chem., 2004, 279 (41), 43000-7.

[71] Gavigan, C.S.; Dalton, J.P.; Bell, A. The role of aminopeptidases in haemoglobin degradation in Plasmodium falciparum-infected erythrocytes. Mol. Biochem. Parasitol., 2001, 117 (1), 37-48.

[72] Atamna, H.; Ginsburg, H. Origin of reactive oxygen species in erythrocytes infected with Plasmodium falciparum. Mol. Biochem. Parasitol., 1993, 61 (2), 231-41. 
[73] Pagola, S.; Stephens, P.W.; Bohle, D.S.; Kosar, A.D.; Madsen, S.K. The structure of malaria pigment beta-haematin. Nature. 2000, 404 (6775), 30710 .

[74] Rosenthal, P.J.; Sijwali, P.S.; Singh, A.; Shenai, B.R. Cysteine proteases of malaria parasites: targets for chemotherapy. Curr. Pharm. Des., 2002, 8 (18), 1659-72.

[75] Rosenthal, P.J.; Wollish, W.S.; Palmer, J.T.; Rasnick, D. Antimalarial effects of peptide inhibitors of a Plasmodium falciparum cysteine proteinase. J. Clin. Invest., 1991, 88 (5), 1467-72.

[76] Salmon, B.L.; Oksman, A.; Goldberg, D.E. Malaria parasite exit from the host erythrocyte: a two-step process requiring extraerythrocytic proteolysis. Proc. Natl. Acad. Sci. U S A. 2001, 98 (1), 271-6.

[77] Pandey, K.C.; Wang, S.X.; Sijwali, P.S.; Lau, A.L.; McKerrow, J.H. Rosenthal, P.J. The Plasmodium falciparum cysteine protease falcipain-2 captures its substrate, hemoglobin, via a unique motif. Proc. Natl. Acad. Sci. U S A. 2005, 102 (26), 9138-43.

[78] Singh, A.; Rosenthal, P.J. Comparison of efficacies of cysteine protease inhibitors against five strains of Plasmodium falciparum. Antimicrob. Agents Chemother, 2001, 45 (3), 949-51.

[79] Sijwali, P.S.; Kato, K.; Seydel, K.B.; Gut, J.; Lehman, J ; Klemba, M. Goldberg, D.E.; Miller, L.H.; Rosenthal, P.J. Plasmodium falciparum cysteine protease falcipain-1 is not essential in erythrocytic stage malaria parasites. Proc. Natl. Acad. Sci. U S A. 2004, 101 (23), 8721-6.

[80] Sijwali, P.S.; Shenai, B.R.; Gut, J.; Singh, A.; Rosenthal, P.J. Expression and characterization of the Plasmodium falciparum haemoglobinase falcipain-3. Biochem. J., 2001, 360 (Pt 2), 481-9.

[81] Singh, N.; Sijwali, P.S.; Pandey, K.C.; Rosenthal, P.J. Plasmodium falciparum: biochemical characterization of the cysteine protease falcipain-2'. Exp. Parasitol., 2006, 112 (3), 187-92.

[82] Goh, L.L.; Sim, T.S. Characterization of amino acid variation at strategic positions in parasite and human proteases for selective inhibition of falcipains in Plasmodium falciparum. Biochem. Biophys. Res. Commun., 2005, 335 (3), 762-70.

[83] Eksi, S.; Czesny, B.; Greenbaum, D.C.; Bogyo, M.; Williamson, K.C. Targeted disruption of Plasmodium falciparum cysteine protease, falcipain 1, reduces oocyst production, not erythrocytic stage growth. Mol. Microbiol., 2004, 53 (1), 243-50.

[84] Greenbaum, D.C.; Baruch, A.; Grainger, M.; Bozdech, Z.; Medzihradszky, K.F.; Engel, J.; DeRisi, J.; Holder, A.A.; Bogyo, M. A role for the protease falcipain 1 in host cell invasion by the human malaria parasite. Science. 2002, 298 (5600), 2002-6.

[85] Kumar, A.; Kumar, K.; Korde, R.; Puri, S.K.; Malhotra, P.; Singh Chauhan, V. Falcipain-1, a Plasmodium falciparum cysteine protease with vaccine potential. Infect. Immun., 2007, 75 (4), 2026-34.

[86] Nielsen, K.M.; Kasper, J.; Choi, M.; Bedford, T.; Kristiansen, K.; Wirth, D.F.; Volkman, S.K.; Lozovsky, E.R.; Hartl, D.L. Gene conversion as a source of nucleotide diversity in Plasmodium falciparum. Mol. Biol. Evol., 2003, 20 (5), 726-34

[87] Drew, M.E.; Banerjee, R.; Uffman, E.W.; Gilbertson, S.; Rosenthal, P.J.; Goldberg, D.E. Plasmodium food vacuole plasmepsins are activated by falcipains. J. Biol. Chem., 2008, 283 (19), 12870-6.

[88] Pandey, K.C.; Singh, N.; Arastu-Kapur, S.; Bogyo, M.; Rosenthal, P.J. Falstatin, a cysteine protease inhibitor of Plasmodium falciparum, facilitates erythrocyte invasion. PLoS Pathog., 2006, 2 (11), e117.

[89] Goh, L.L.; Sim, T.S. Homology modeling and mutagenesis analyses of Plasmodium falciparum falcipain 2A: implications for rational drug design. Biochem. Biophys. Res. Commun., 2004, 323 (2), 565-72.

[90] Korde, R.; Bhardwaj, A.; Singh, R.; Srivastava, A.; Chauhan, V.S.; Bhatnagar, R.K.; Malhotra, P. A prodomain peptide of Plasmodium falciparum cysteine protease (falcipain-2) inhibits malaria parasite development. J. Med. Chem., 2008, 51 (11), 3116-23.

[91] Sijwali, P.S.; Shenai, B.R.; Rosenthal, P.J. Folding of the Plasmodium falciparum cysteine protease falcipain- 2 is mediated by a chaperone-like peptide and not the prodomain. J. Biol. Chem., 2002, 277 (17), 14910-5.

[92] Wang, S.X.; Pandey, K.C.; Somoza, J.R.; Sijwali, P.S.; Kortemme, T.; Brinen, L.S.; Fletterick, R.J.; Rosenthal, P.J.; McKerrow, J.H. Structural basis for unique mechanisms of folding and hemoglobin binding by a malarial protease. Proc. Natl. Acad. Sci. U S A. 2006, 103 (31), 11503-8.

[93] Leung, D.; Abbenante, G.; Fairlie, D.P. Protease inhibitors: current status and future prospects. J. Med. Chem., 2000, 43 (3), 305-41.

[94] Schechter, I.; Berger, A. On the size of the active site in proteases. I. Papain. Biochem. Biophys. Res. Commun., 1967, 27 (2), 157-62.

[95] Sajid, M.; McKerrow, J.H. Cysteine proteases of parasitic organisms. Mol. Biochem. Parasitol., 2002, 120 (1), 1-21.

[96] Batra, S.; Sabnis, Y.A.; Rosenthal, P.J.; Avery, M.A. Structure-based approach to falcipain-2 inhibitors: synthesis and biological evaluation of 1,6,7-trisubstituted dihydroisoquinolines and isoquinolines. Bioorg. Med. Chem., 2003, 11 (10), 2293-9.

[97] Rosenthal, P.J.; Lee, G.K.; Smith, R.E. Inhibition of a Plasmodium vinckei cysteine proteinase cures murine malaria. J. Clin. Invest., 1993, 91 (3), 10526 .

[98] Rosenthal, P.J.; Olson, J.E.; Lee, G.K.; Palmer, J.T.; Klaus, J.L.; Rasnick, D. Antimalarial effects of vinyl sulfone cysteine proteinase inhibitors. Antimicrob. Agents Chemother., 1996, 40 (7), 1600-3.
[99] Shenai, B.R; Lee, B.J ; Alvarez-Hernandez, A; Chong, P. ; Emal, C.D; Neitz, R.J.; Roush, W.R.; Rosenthal, P.J. Structure-activity relationships for inhibition of cysteine protease activity and development of Plasmodium falciparum by peptidyl vinyl sulfones. Antimicrob. Agents Chemother., 2003 47 (1), 154-60

[100] Powers, J.C.; Asgian, J.L.; Ekici, O.D.; James, K.E. Irreversible inhibitors of serine, cysteine, and threonine proteases. Chem. Rev., 2002, 102 (12), 4639750

[101] Palmer, J.T.; Rasnick, D.; Klaus, J.L.; Bromme, D. Vinyl sulfones as mechanism-based cysteine protease inhibitors. J. Med. Chem., 1995, 38 (17), 3193-6.

[102] Vicik, R.; Busemann, M.; Baumann, K.; Schirmeister, T. Inhibitors of cysteine proteases. Curr. Top. Med. Chem., 2006, 6 (4), 331-53.

[103] Lee, B.J.; Singh, A.; Chiang, P.; Kemp, S.J.; Goldman, E.A.; Weinhouse, M.I.; Vlasuk, G.P.; Rosenthal, P.J. Antimalarial activities of novel synthetic cysteine protease inhibitors. Antimicrob. Agents Chemother., 2003, 47 (12), 3810-4

[104] Schulz, F.; Gelhaus, C.; Degel, B.; Vicik, R.; Heppner, S.; Breuning, A.; Leippe, M.; Gut, J.; Rosenthal, P.J.; Schirmeister, T. Screening of protease inhibitors as antiplasmodial agents. Part I: Aziridines and epoxides. ChemMedChem. 2007, 2 (8), 1214-24.

[105] Martichonok, V.; Plouffe, C.; Storer, A.C.; Menard, R.; Jones, J.B. Aziridine analogs of [[trans-(epoxysuccinyl)-L-leucyl]amino]-4-guanidinobutane (E64) as inhibitors of cysteine proteases. J. Med. Chem., 1995, 38 (16), 3078 85 .

[106] Micale, N.; Kozikowski, A.P.; Ettari, R.; Grasso, S.; Zappala, M.; Jeong, J.J.; Kumar, A.; Hanspal, M.; Chishti, A.H. Novel peptidomimetic cysteine protease inhibitors as potential antimalarial agents. J. Med. Chem., 2006, 49 (11), 3064-7.

[107] Verissimo, E.; Berry, N.; Gibbons, P.; Cristiano, M.L.; Rosenthal, P.J.; Gut, J.; Ward, S.A.; O'Neill, P.M. Design and synthesis of novel 2-pyridone peptidomimetic falcipain $2 / 3$ inhibitors. Bioorg. Med. Chem. Lett., 2008, 18 (14), 4210-4.

[108] Schirmeister, T.; Kaeppler, U. Non-peptidic inhibitors of cysteine proteases. Mini Rev. Med. Chem., 2003, 3 (4), 361-73.

[109] Chiyanzu, I.; Hansell, E.; Gut, J.; Rosenthal, P.J.; McKerrow, J.H.; Chibale, $\mathrm{K}$. Synthesis and evaluation of isatins and thiosemicarbazone derivatives against cruzain, falcipain-2 and rhodesain. Bioorg. Med. Chem. Lett., 2003, 13 (20), 3527-30.

[110] Marti-Renom, M.A.; Stuart, A.C.; Fiser, A.; Sanchez, R.; Melo, F.; Sali, A. Comparative protein structure modeling of genes and genomes. Annu. Rev. Biophys. Biomol. Struct., 2000, 29, 291-325.

[111] Oshiro, C.; Bradley, E.K; Eksterowicz, J; Evensen, E. Lamb, M.L Lanctot, J.K.; Putta, S.; Stanton, R.; Grootenhuis, P.D. Performance of 3D database molecular docking studies into homology models. J. Med. Chem. 2004, 47 (3), 764-7.

[112] Ring, C.S.; Sun, E.; McKerrow, J.H.; Lee, G.K.; Rosenthal, P.J.; Kuntz, I.D.; Cohen, F.E. Structure-based inhibitor design by using protein models for the development of antiparasitic agents. Proc. Natl. Acad. Sci. U S A. 1993, 90 (8), 3583-7.

[113] Sabnis, Y.; Rosenthal, P.J.; Desai, P.; Avery, M.A. Homology modeling of falcipain-2: validation, de novo ligand design and synthesis of novel inhibitors. J. Biomol. Struct. Dyn., 2002, 19 (5), 765-74.

[114] Hogg, T.; Nagarajan, K.; Herzberg, S.; Chen, L.; Shen, X.; Jiang, H.; Wecke, M.; Blohmke, C.; Hilgenfeld, R.; Schmidt, C.L. Structural and functional characterization of Falcipain-2, a hemoglobinase from the malarial parasite Plasmodium falciparum. J. Biol. Chem., 2006, 281 (35), 25425-37.

[115] Wang, S.X.; Pandey, K.C.; Scharfstein, J.; Whisstock, J.; Huang, R.K.; Jacobelli, J.; Fletterick, R.J.; Rosenthal, P.J.; Abrahamson, M.; Brinen, L.S.; Rossi, A.; Sali, A.; McKerrow, J.H. The structure of chagasin in complex with a cysteine protease clarifies the binding mode and evolution of an inhibitor family. Structure. 2007, 15 (5), 535-43.

[116] Kerr, I.D.; Lee, J.H.; Pandey, K.C.; Harrison, A.; Sajid, M.; Rosenthal, P.J Brinen, L.S. Structures of falcipain-2 and falcipain-3 bound to small molecule inhibitors: implications for substrate specificity. J. Med. Chem., 2009, 52 (3), 852-7.

[117] Kerr, I.D.; Lee, J.H.; Farady, C.J.; Marion, R.; Rickert, M.; Sajid, M.; Pandey, K.C.; Caffrey, C.R.; Legac, J.; Hansell, E.; McKerrow, J.H.; Craik, C.S.; Rosenthal, P.J.; Brinen, L.S. Vinyl sulfones as antiparasitic agents and a structural basis for drug design. J. Biol. Chem., 2009, 284 (38), 25697-703.

[118] Kumar, A.; Dasaradhi, P.V.; Chauhan, V.S.; Malhotra, P. Exploring the role of putative active site amino acids and pro-region motif of recombinan falcipain-2: a principal hemoglobinase of Plasmodium falciparum. Biochem. Biophys. Res. Commun., 2004, 317 (1), 38-45.

[119] Pandey, K.C.; Barkan, D.T.; Sali, A.; Rosenthal, P.J. Regulatory elements within the prodomain of Falcipain-2, a cysteine protease of the malaria parasite Plasmodium falciparum. PLoS One. 2009, 4 (5), e5694.

[120] Taylor, R.D.; Jewsbury, P.J.; Essex, J.W. A review of protein-small molecule docking methods. J. Comput. Aided Mol. Des., 2002, 16 (3), 151-66.

[121] Jones, G.; Willett, P.; Glen, R.C. Molecular recognition of receptor sites using a genetic algorithm with a description of desolvation. J. Mol. Biol., 1995, 245 (1), 43-53 
[122] Jones, G.; Willett, P.; Glen, R.C.; Leach, A.R.; Taylor, R. Development and validation of a genetic algorithm for flexible docking. J. Mol. Biol., 1997, 267 (3), 727-48

[123] Friesner, R.A.; Banks, J.L.; Murphy, R.B.; Halgren, T.A.; Klicic, J.J.; Mainz, D.T.; Repasky, M.P.; Knoll, E.H.; Shelley, M.; Perry, J.K.; Shaw, D.E.; Francis, P.; Shenkin, P.S. Glide: a new approach for rapid, accurate docking and scoring. 1. Method and assessment of docking accuracy. J. Med. Chem., 2004, 47 (7), 1739-49.

[124] Halgren, T.A.; Murphy, R.B.; Friesner, R.A.; Beard, H.S.; Frye, L.L.; Pollard, W.T.; Banks, J.L. Glide: a new approach for rapid, accurate docking and scoring. 2. Enrichment factors in database screening. J. Med. Chem., 2004, 47 (7), 1750-9.

[125] Ewing, T.J.; Makino, S.; Skillman, A.G.; Kuntz, I.D. DOCK 4.0: search strategies for automated molecular docking of flexible molecule databases. $J$. Comput. Aided Mol. Des., 2001, 15 (5), 411-28.

[126] Morris, G.M.; Goodsell, D.S.; Halliday, R.S.; Huey, R.; Hart, W.E.; Belew, R.K.; Olson, A.J. Automated Docking Using a Lamarckian Genetic Algorithm and an Empirical Binding Free Energy Function. J. Comput. Chem., 1998, 19, 1639-1662.

[127] Bissantz, C.; Folkers, G.; Rognan, D. Protein-based virtual screening of chemical databases. 1. Evaluation of different docking/scoring combinations. J. Med. Chem., 2000, 43 (25), 4759-67.

[128] Shoichet, B.K. Virtual screening of chemical libraries. Nature. 2004, 432 (7019), 862-5.

[129] Desai, P.V.; Patny, A.; Sabnis, Y.; Tekwani, B.; Gut, J.; Rosenthal, P.; Srivastava, A.; Avery, M. Identification of novel parasitic cysteine protease inhibitors using virtual screening. 1. The ChemBridge database. J. Med. Chem., 2004, 47 (26), 6609-15.

[130] Desai, P.V.; Patny, A.; Gut, J.; Rosenthal, P.J.; Tekwani, B.; Srivastava, A.; Avery, M. Identification of novel parasitic cysteine protease inhibitors by use of virtual screening. 2. The available chemical directory. J. Med. Chem., 2006, 49 (5), 1576-84.

[131] Lipinski, C.; Lombardo, F.; Dominy, B.; Feeney, P. Experimental and computational approaches to estimate solubility and permeability in drug discovery and development settings. Adv. Drug Delivery Rev., 1997, 23, 325 .

[132] Li, H.; Huang, J.; Chen, L.; Liu, X.; Chen, T.; Zhu, J.; Lu, W.; Shen, X.; Li, J.; Hilgenfeld, R.; Jiang, H. Identification of novel falcipain-2 inhibitors as potential antimalarial agents through structure-based virtual screening. $J$. Med. Chem., 2009, 52 (15), 4936-40.

[133] Li, H.; Li, C.; Gui, C.; Luo, X.; Chen, K.; Shen, J.; Wang, X.; Jiang, H. GAsDock: a new approach for rapid flexible docking based on an improved multi-population genetic algorithm. Bioorg. Med. Chem. Lett., 2004, 14 (18), 4671-6.
[134] Goud, P.M - Sheri, A.; Desai, P. V ; Watkins, E B - Tekwani, B - Sabnis, Y Gut, J.; Rosenthal, P.J.; Avery, M.A. Design, synthesis and evaluation of Trisubstituted Thiazoles Targeting Plasmodium Falciparum Cysteine Proteases. Med. Chem. Res., 2005, 14 (2), 74-105.

[135] Cieplak, P.; Kollman, P.A. A technique to study molecular recognition in drug design: preliminary application of free energy derivatives to inhibition of a malarial cysteine protease. J. Mol. Recognit., 1996, 9 (2), 103-12.

[136] Li, Z.; Chen, X.; Davidson, E.; Zwang, O.; Mendis, C.; Ring, C.S.; Roush, W.R.; Fegley, G.; Li, R.; Rosenthal, P.J.; et al. Anti-malarial drug development using models of enzyme structure. Chem. Biol., 1994, 1 (1), 317.

[137] Buback, V.; Mladenovic, M.; Engels, B.; Schirmeister, T. Rational design of improved aziridine-based inhibitors of cysteine proteases. J. Phys. Chem. B. 2009, 113 (15), 5282-9.

[138] Helten, H.; Schirmeister, T.; Engels, B. Model Calculations about the Influence of Protic Environments on the Alkylation Step of Epoxide, Aziridine, and Thiirane Based Cysteine Proteases Inhibitors. J. Phys. Chem. A. 2004, 108, 7691-7701.

[139] Helten, H.; Schirmeister, T.; Engels, B. Theoretical studies about the influence of different ring substituents on the nucleophilic ring opening of three-membered heterocycles and possible implications for the mechanisms of cysteine protease inhibitors. J. Org. Chem., 2005, 70 (1), 233-7.

[140] Mladenovic, M.; Schirmeister, T.; Thiel, S.; Thiel, W.; Engels, B. The importance of the active site histidine for the activity of epoxide- or aziridine-based inhibitors of cysteine proteases. ChemMedChem. 2007, 2 (1), $120-8$.

[141] Vicik, R.; Helten, H.; Schirmeister, T.; Engels, B. Rational design of aziridine-containing cysteine protease inhibitors with improved potency: studies on inhibition mechanism. ChemMedChem. 2006, 1 (9), 1021-8.

[142] Sant'anna, C.M.R.; Alencastro, R.B.; Rodrigues, C.R.; Barreiro, G.; Barreiro, E.; Neto, J.; Freitas, A.C.C. A Semiempirical Study of Pyrazole Acylhydrazones as Potential Antimalarial Agents. Int. J. Quantum Chem. 1996, $23,1835-1843$. 